\title{
Mechanism-Based FE Simulation of Tool Wear in Diamond Drilling of $\mathrm{SiC}_{\mathrm{p}} / \mathrm{Al}$ Composites
}

\author{
Junfeng Xiang ${ }^{1}$, Siqin Pang ${ }^{1,2}$, Lijing Xie ${ }^{1,2, *}$, Feinong Gao ${ }^{1}$, Xin Hu ${ }^{1}$, Jie $\mathrm{Yi}^{1}$ and Fang Hu ${ }^{1}$ \\ 1 School of Mechanical Engineering, Beijing Institute of Technology, Beijing 100081, China; \\ xiang_junfeng@126.com (J.X.); pangsq@yeah.net (S.P.); 2120170328@bit.edu.cn (F.G.); \\ 13810438099@163.com (X.H.); 3120140175@bit.edu.cn (J.Y.); songyl1919@163.com (F.H.) \\ 2 Key Laboratory of Advanced Machining, Beijing Institute of Technology, Beijing 100081, China \\ * Correspondence: rita_xie2004@163.com
}

Received: 18 January 2018; Accepted: 5 February 2018; Published: 7 February 2018

\begin{abstract}
The aim of this work is to analyze the micro mechanisms underlying the wear of macroscale tools during diamond machining of $\mathrm{SiC}_{\mathrm{p}} / \mathrm{Al} 6063$ composites and to develop the mechanism-based diamond wear model in relation to the dominant wear behaviors. During drilling, high volume fraction $\mathrm{SiC}_{\mathrm{p}} / \mathrm{Al} 6063$ composites containing $\mathrm{Cu}$, the dominant wear mechanisms of diamond tool involve thermodynamically activated physicochemical wear due to diamond-graphite transformation catalyzed by $\mathrm{Cu}$ in air atmosphere and mechanically driven abrasive wear due to high-frequency scrape of hard $\mathrm{SiC}$ reinforcement on tool surface. An analytical diamond wear model, coupling Usui abrasive wear model and Arrhenius extended graphitization wear model was proposed and implemented through a user-defined subroutine for tool wear estimates. Tool wear estimate in diamond drilling of $\mathrm{SiC}_{\mathrm{p}} / \mathrm{Al} 6063$ composites was achieved by incorporating the combined abrasive-chemical tool wear subroutine into the coupled thermomechanical FE model of 3D drilling. The developed drilling FE model for reproducing diamond tool wear was validated for feasibility and reliability by comparing numerically simulated tool wear morphology and experimentally observed results after drilling a hole using brazed polycrystalline diamond (PCD) and chemical vapor deposition (CVD) diamond coated tools. A fairly good agreement of experimental and simulated results in cutting forces, chip and tool wear morphologies demonstrates that the developed 3D drilling FE model, combined with a subroutine for diamond tool wear estimate can provide a more accurate analysis not only in cutting forces and chip shape but also in tool wear behavior during drilling $\mathrm{SiC}_{\mathrm{p}} / \mathrm{Al} 6063$ composites. Once validated and calibrated, the developed diamond tool wear model in conjunction with other machining FE models can be easily extended to the investigation of tool wear evolution with various diamond tool geometries and other machining processes in cutting different workpiece materials.
\end{abstract}

Keywords: diamond tool; drilling; abrasive-chemical wear; graphitization; finite element; $\mathrm{SiC}_{\mathrm{p}} / \mathrm{Al} 6063$ composites

\section{Introduction}

Silicon carbide particulate reinforced aluminum matrix $\left(\mathrm{SiC}_{\mathrm{p}} / \mathrm{Al}\right)$ composites have been of great potential due to their superior physical and mechanical properties, such as high stiffness-to-weight ratio, high specific strength, high wear resistance, low sensitivity to temperature variations and excellent corrosion resistance [1]. This composite material has a promising application prospect in many advanced industries such as aerospace, marine, automotive and sport equipment [2,3]. However, $\mathrm{SiC}_{\mathrm{p}} / \mathrm{Al}$ composites are limited in the actual production applications by their poor machinability since the hard $\mathrm{SiC}$ particles in the aluminum matrix lead to serious tool wear and undesired surface quality $[4,5]$. 
In cutting $\mathrm{SiC}_{\mathrm{p}} / \mathrm{Al}$ composites, the conventional tools such as high-speed steel (HSS) and ceramics easily suffer from rapid tool wear, poor hole quality and higher cutting forces induced by tool wear [6-8]. Although the carbide tools are found to be superior machining performance to HSS and ceramics tools but fail to perform well in machining $\mathrm{SiC}_{\mathrm{p}} / \mathrm{Al}$ composites with $\mathrm{SiC}$ volume fraction higher than 50\% [9] due to severe tool wear. Hence, the diamond, diamond coated and diamond-like tools are considered one of the most favorable ones for cutting these materials [10,11].

Since progressive tool wear can weaken tool structure, cause obvious increase in cutting force and eventually lead to poor surface finish and catastrophic failure of cutting tools, the capability of predicting contribution of miscellaneous wear mechanisms to tool wear is very helpful for the selection of tool materials, redesign of tool geometry and optimization of cutting process [12]. Over the past several decades, the research upon tool wear has been mainly based on empirical method or experimental investigation [13,14]. Due to the excessive process parameters influencing tool wear, numerous cutting experiments need to be carried out to develop empirical relationships among them. Based on Taylor's basic and extended equations, the empirical tool life models under very limited cutting conditions were developed. Many models based on extended Taylor's tool life equation involving process variables were developed to describe more reliable tool life estimates and to extend its applicability to other cutting technologies. Colding [15] extended a generalized tool life estimate to a variety of machining technologies and derived the relationship between process parameters and tool life. Such relation has been modified further by Choudhury [16] that take into account tool geometry to achieve more accurate estimate for tool life, which in turn was used to maximize tool life subject to practical cutting conditions. However, although this empirical approach for tool life estimates aimed at some specific materials and tool geometries has gained a certain popularity, its applicability in solving general problems of tool wear is severely limited due to the lack of inherent physical meaning in these empirical life models. And only characterized by sufficient process parameters can these empirical models estimate tool life more accurately but the cost of tool wear experiments for identifying model parameters is often heavy. Moreover, except for the available tool life based on empirical Taylor model, it is impossible to get further information upon the tool wear progress, worn geometry, or even wear mechanism in different tool zones which are sometimes necessary and important for tool design and tool material selection [17]. Issues with empirical approach of tool life testing were identified. Regarding tool life testing, there are some ISO standard, e.g., ISO 8688-2 [18], which recommends testing procedure, tool wear modes, etc.

To establish the tool wear model with less process variables that can provide accurate tool life estimate and more wear details, many studies [19-22] were dedicated to developing the tool wear analytical models. These analytical models were characterized as the effects of internal variables such as the temperature at the tool-workpiece interface, stresses at the tool surface, relative sliding velocity between the tool and workpiece and microstructure of the tool and workpiece on tool wear in different wear modes involving abrasion, adhesion and diffusion. Among all analytical wear models, the wear one proposed by Takeyama [21] is used to describe the combined effect of mechanical abrasion proportional to sliding velocity and thermally activated diffusion in relation to interface temperature and activation energy for diffusion. Subsequently, the research of Usui [22], based on Shaw' adhesive wear model [23], derived tool wear equation to incorporate the influence of interface temperature, relative sliding velocity, interface pressure upon tool wear rate. Actually, these analytical models cannot be applied directly for wear estimate since the thermomechanical loads near cutting edges keep changing with cutting conditions and tool wear evolution [24]. It is necessary to require the knowledge of these internal variables near cutting edges under different cutting conditions and their variation in tool wear evolution process. Therefore, some researchers have adopted experimental or analytical approaches to provide these inputs of internal variables as a function of cutting parameters and tool wear geometry $[25,26]$. However, in terms of difficulty of modeling a continuously progressive wear process and ever-changing process variables in predicting tool wear evolution, the popularity of this analytical modeling approach is also limited. 
With rapidly increasing computer power and continually developing numerical methods, some attempts were made to numerically simulate cutting process, to calculate the thermo-mechanical loading histories and other process variables during cutting and in conjunction with analytical wear model to arrive at tool wear evolution at the cutting edges with reasonable accuracy. Therefore, some simulation has been implemented to reproduce tool wear evolution by integrating the above analytical wear models and cutting numerical models. The pioneering research of Xie [27] developed a 2D FE-based tool wear procedure based on the Python user program to predict the progression of tool wear. During each calculation cycle (time increment) of tool wear, FE analysis of chip formation and heat conduction during steady-state cutting was made to extract the process variables information essential for the inputs of Usui abrasive wear analytical model. According to the calculated wear rate, the tool nodal displacement in each time increment was obtained and hence the worn geometry can be updated based on nodal displacement. The next FE analysis cycle for predicting tool wear continued in an updated worn geometry until a use-defined tool reshape criterion was reached. Attanasio [28] extended the 3D FE simulation of tool wear by integrating the abrasive wear model proposed by Usui [22] and the high-temp diffusion wear model of Takeyama [21] to achieve a satisfactory wear estimate for 3D turning. Although some work has successfully reproduced the tool wear morphology in the experimental tests using the developed numerical models based description of different mechanical and physical wear mechanisms, 3D simulation of diamond physicochemical wear regarding the graphitization involving transformation of diamond into graphite and diffusion of newly-formed graphite into the workpiece has not yet been reported in metal cutting, especially for drilling. What's noteworthy about modelling diamond physicochemical wear is that several researchers have attempted to mimic the transformation of tetrahedral diamond into hexagonal close-packing graphite and subsequent diffusion of graphite into transition metals and their alloys and find out suitable crystal orientations resistant to graphitization, using Molecular Dynamics method [29,30]. Unfortunately, Molecular Dynamics are used solely for simulating material removal process at nanoscale well within several hundred nanoseconds due to the combined limitations in available computer power, numerical methods and computational cost [12]. The aim of this paper is hence to analyze machining induced wear mechanisms underlying macroscale wear behavior and develop tool wear FE model based analytical description of wear mechanisms in diamond drilling of $\mathrm{SiC}_{\mathrm{p}} / \mathrm{Al}$ composites. This was achieved by incorporating a combination of Usui wear model and graphitization induced chemical wear model into 3D FE model of diamond drilling as follows.

\section{Experimental Work}

\subsection{Experimental Setup}

The material employed for the drilling tests was Al6063 matrix composites reinforced by $65 \%$ volume fraction $\mathrm{SiC}$ particulates $\left(\mathrm{Al} 6063 / \mathrm{SiC}_{\mathrm{p}} / 65 \mathrm{p}\right.$ composites) fabricated through vacuum infiltration method. Figure 1 shows the microstructure of $\mathrm{Al6063} / \mathrm{SiC}_{\mathrm{p}} / 65 \mathrm{p}$ composites, in which $\mathrm{SiC}$ particulates are homogeneously distributed and not obviously clustered in the aluminum matrix. Its chemical composition determined using Energy-dispersive X-ray spectroscopy is given in Table 1. The drilling tests were performed on a DMU 80 monoblock machining center, equipped with a rotating 4-Component Dynamometer Kistler 9123 (Kistler Instrument China Ltd., Shanghai, China), as is shown in Figure 2. The wear morphologies of cutting tools were examined using 3D Laser Scanning Microscope VK-X200 (Keyence, Osaka, Japan). The measurement of drilling forces in machining was implemented using Kistler 9123. In this paper, the brazed polycrystalline diamond (PCD) drill and chemical vapor deposition (CVD) diamond coated drill were used to perform the cutting of $\mathrm{Al} 6063 / \mathrm{SiC}_{\mathrm{p}} / 65 \mathrm{p}$ composites. A summary of the experimental details upon tooling, workpiece and drilling conditions are given in Table 2. 


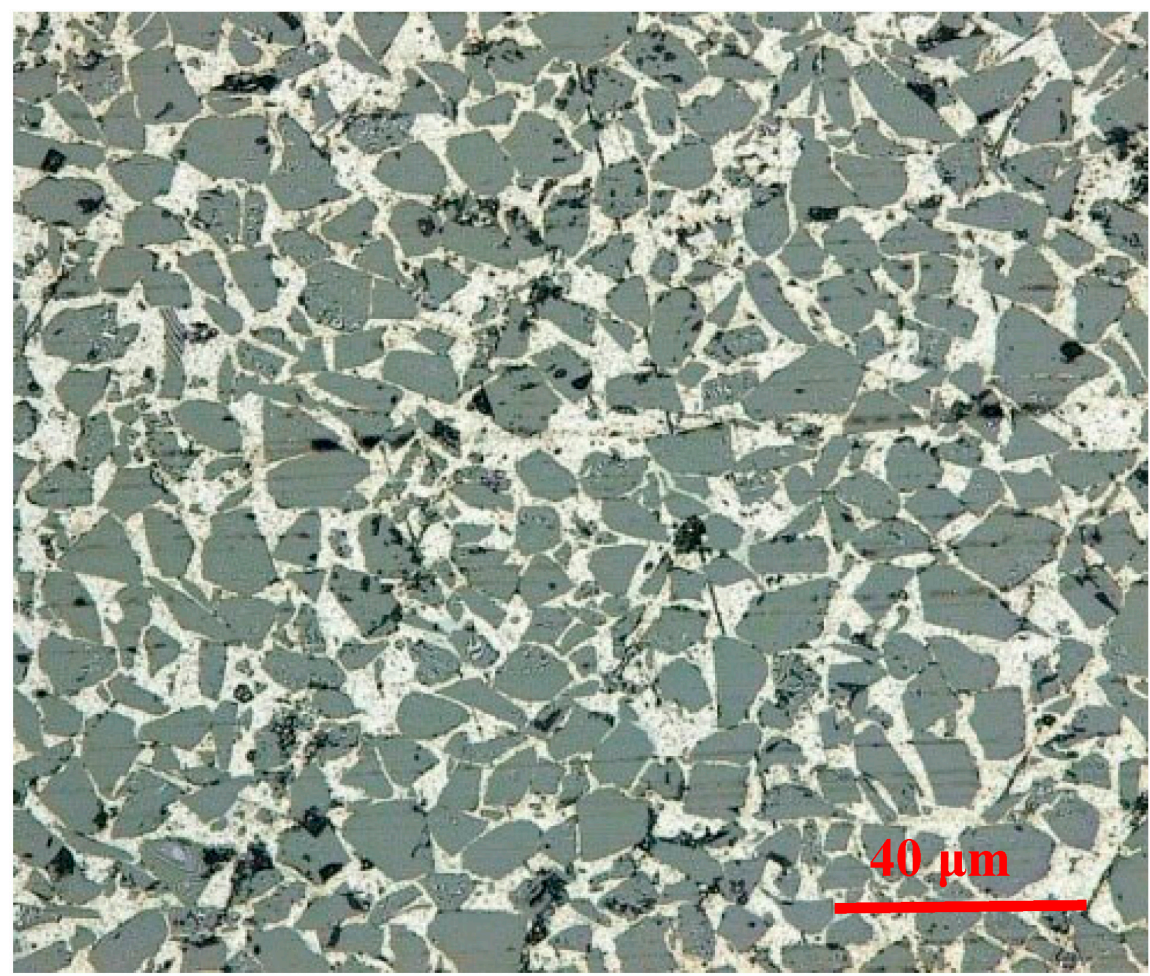

Figure 1. Micrograph of $\mathrm{Al} 6063 / \mathrm{SiC}_{\mathrm{p}} / 65 \mathrm{p}$ composites.

Table 1. Chemical composition of $\mathrm{Al} 6063 / \mathrm{SiC}_{\mathrm{p}} / 65 \mathrm{p}$ composites.

\begin{tabular}{ccccccc}
\hline Element & $\mathbf{A l}$ & $\mathbf{M g}$ & $\mathbf{C u}$ & $\mathbf{S i}$ & $\mathbf{C}$ & Others \\
\hline $\mathrm{wt} \%$ & 38.33 & 0.48 & 1.51 & 51.24 & 8.43 & margin \\
\hline
\end{tabular}

Table 2. Summary of experiment details.

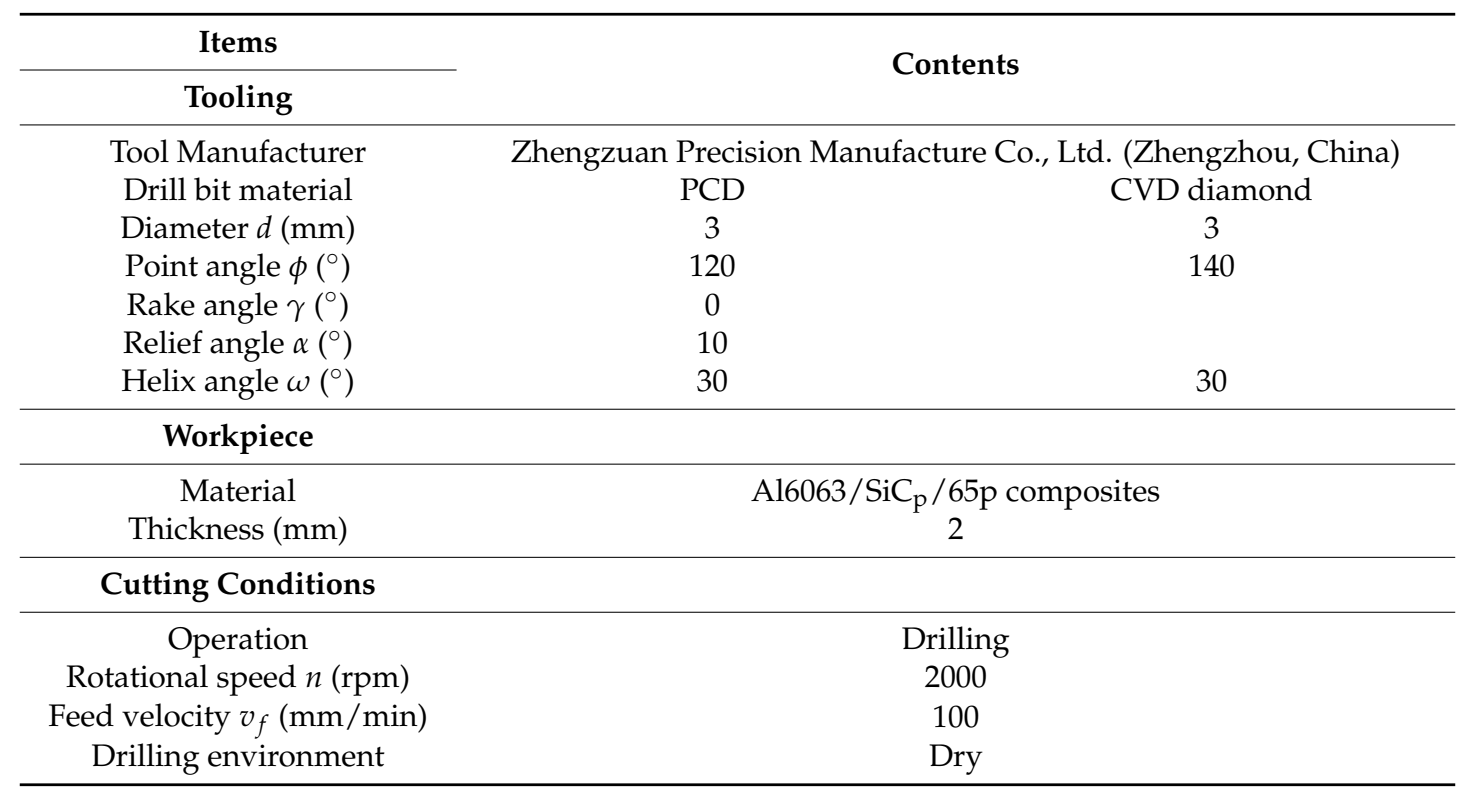



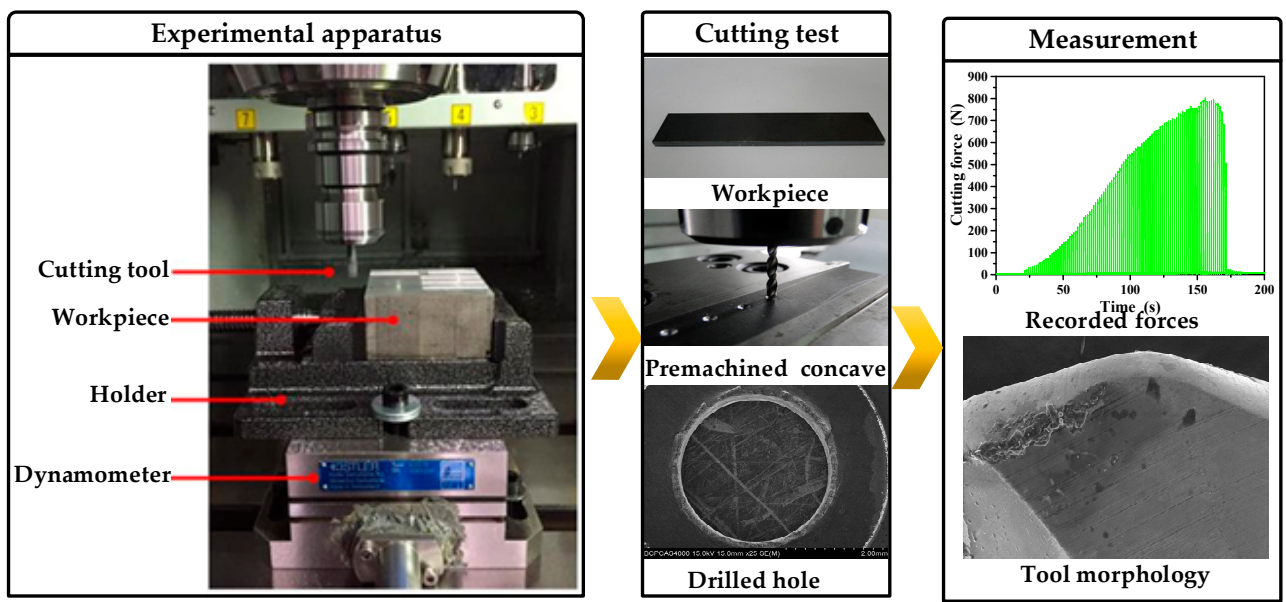

Figure 2. Experimental setup.

\subsection{Wear Mechanisms}

Figure 3 shows the experimental findings of tool wear morphologies after drilling 10th hole using PCD and CVD diamond coated drills. The wear land was formed on the flank faces of PCD and CVD drill bits. The grooves and scratches parallel to cutting direction indicate the tool flank face suffered from severe abrasive wear. The combined action of two-body and multi-body abrasion at the tool-workpiece-chip interface resulted in the formation of flank wear land. The considerable and uneven wear morphologies on the rake face away from cutting lips of PCD drill and irregular wear land on the rake face near cutting lips was suspected to be caused by physicochemical wear.

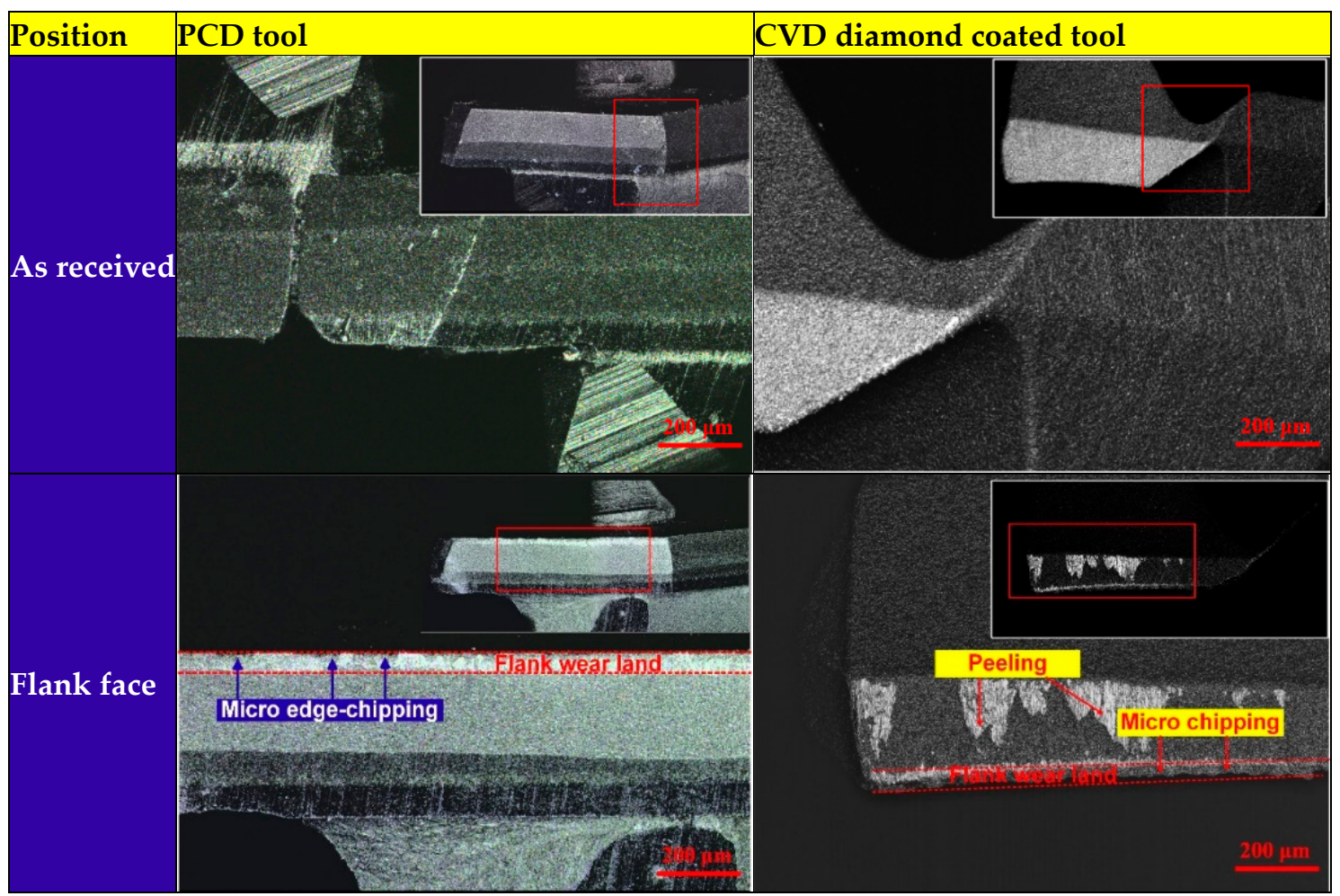

Figure 3. Cont. 


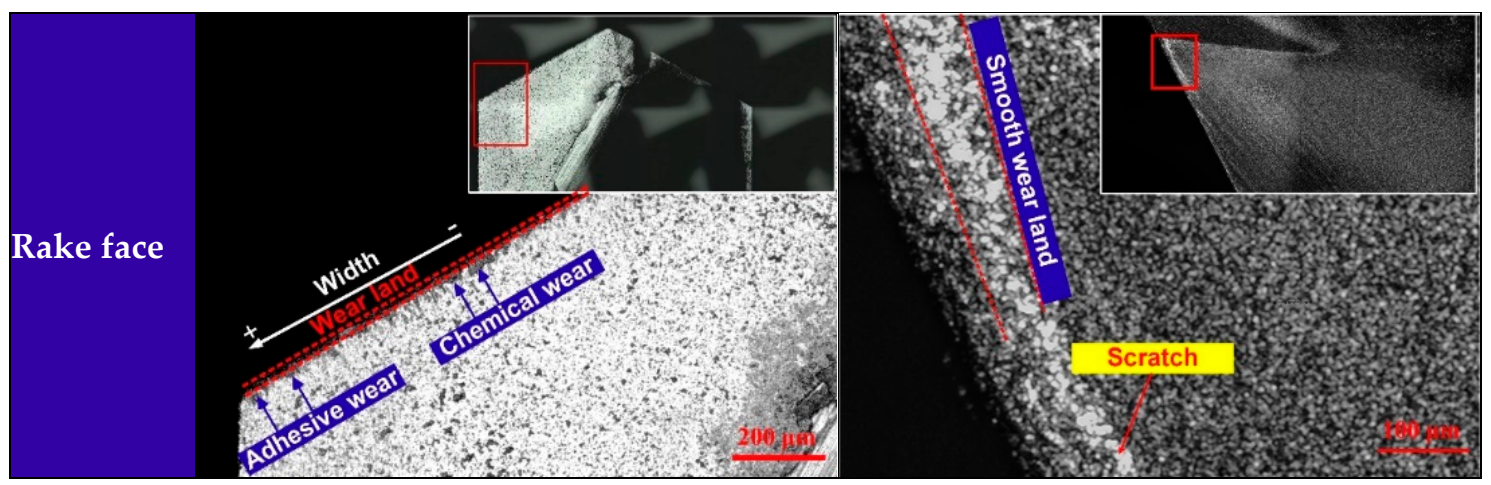

Figure 3. Wear morphologies of PCD and CVD diamond coated tools after drilling $\mathrm{Al6063} / \mathrm{SiC}_{\mathrm{p}} / 65 \mathrm{p}$ composites using 3D Laser Scanning Microscope VK-X200 (Keyence, Osaka, Japan).

Nevertheless, it is well-known that diamond tools cannot be used for cutting effectively transition metals and their alloys due to severe chemical wear. Actually, diamond tools can be used for cutting $\mathrm{Cu}$ and its alloys, although $\mathrm{Cu}$ is transition mental. And the significant graphitization of diamond tool has not been reported during cutting Copper and its alloys. The phase transformation of diamond into graphite during drilling of $\mathrm{Al} 6063 / \mathrm{SiC}_{\mathrm{p}} / 65 \mathrm{p}$ composites containing $\mathrm{Cu}$ is correlated to machining induced thermodynamics conditions with the catalysis of $\mathrm{Cu}$ in air atmosphere. The reciprocating actions of thin graphite layer formed by the oxidation of hydrogen chemisorbed on diamond surface with copper oxides and $\mathrm{SiC}$ particulates' high-frequency scrape on newly-formed graphite film lead to the continual and significant occurrence of diamond graphitization [31]. More details of diamond tools wear during machining of $\mathrm{SiC}_{\mathrm{p}} / \mathrm{Al}$ composites containing $\mathrm{Cu}$ is provided in [31]. It is found experimentally that PCD tool suffered from micro chipping, abrasive wear, adhesive wear and chemical wear, whereas CVD diamond coating tools suffered from abrasive wear, adhesive wear, delamination wear (peeling) and chemical wear. Tool wear in cutting is a complicated evolution process which is not formed by a unique wear mechanism but a combined action of mechanical, physical and chemical wear mechanisms [32,33]. In view of the complexity of tool wear mechanisms and theories, it is almost impossible to implement an overall wear model that considers all wear mechanisms involved in cutting to mimic tool wear progression. A simple but practical way to estimate tool wear is to only take into account those predominant wear mechanisms that occur under certain cutting conditions. The mechanically-induced abrasion and thermodynamically-activated graphitization are the predominant and common wear mechanisms for PCD and CVD tools during drilling $\mathrm{Al} 6063 / \mathrm{SiC}_{\mathrm{p}} / 65 \mathrm{p}$ composites containing $\mathrm{Cu}$.

\section{Results}

Figure 4 shows the flowchart of tool wear calculation procedure using DEFORM 3D FE codes. A 3D incremental Lagrangian drilling model-in which initial tool geometry and an equivalent homogenous material (EHM) based workpiece were incorporated-was established to implement an EHM drilling simulation of $\mathrm{SiC}_{\mathrm{p}} / \mathrm{Al} 6063$ composites. The elasto-plastic workpiece and rigid tool are considered in the Lagrangian drilling model. To reduce computational cost, the modeling of drill bit is only focused on the tool tip part involving realistic drilling and the sharp edges is considered owing to newly-received drill bit employed at the beginning of drilling (Figure 5a). The motions for tool feed and rotation are imposed on the tool center axis. For workpiece modelling, the workpiece part neighbored to the tool tip are accounted for in drilling model and to arrive at stable drilling as soon as possible, a cone-like concave machined surface is firstly pre-built on the workpiece surface, as shown in Figure 5b. 


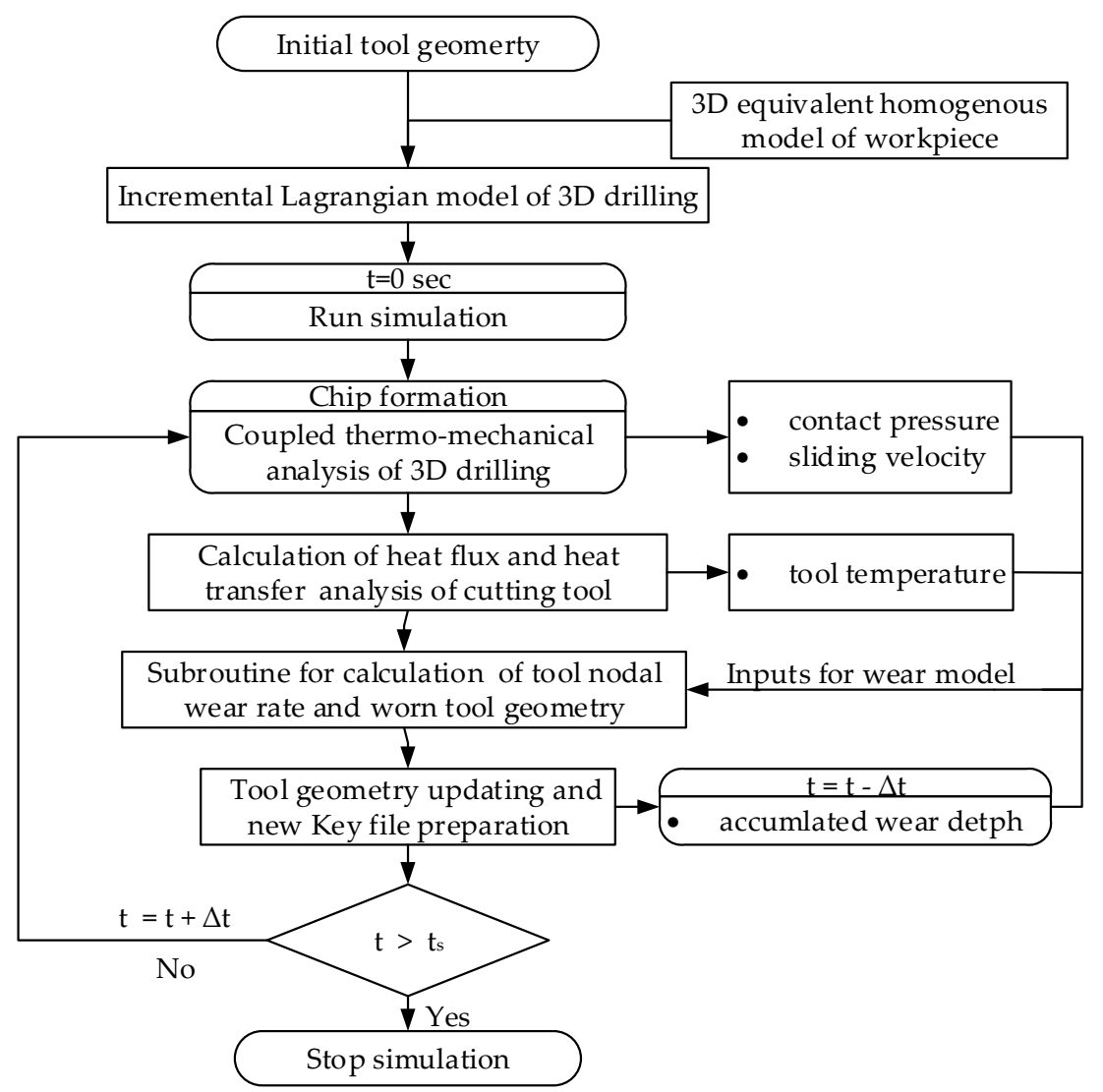

Figure 4. Flowchart of tool wear calculation procedure using FEM.

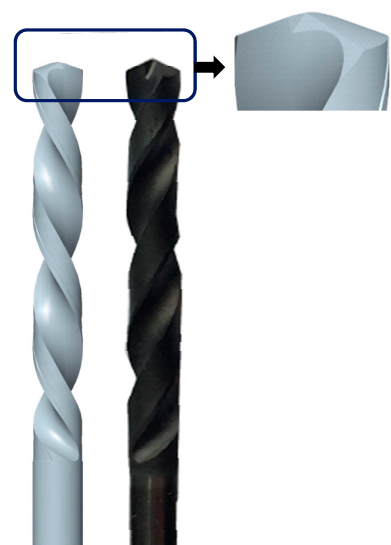

(a)

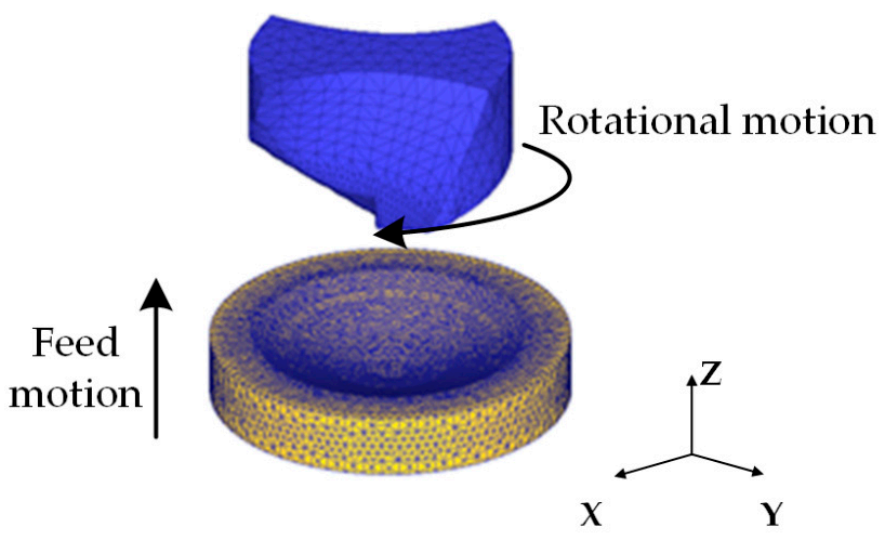

(b)

Figure 5. Drill modelling and simulation: (a) drill simplification; (b) FE modelling of drilling.

The chip formation and heat transfer analysis are implemented by running 3D coupled thermomechanical drilling model to provide the inputs of process variables (contact stress at the tool surface, relative sliding velocity between the chip and tool, temperature at the chip-tool interface) required for tool wear estimate and subsequent tool worn geometry updating. The distributions of these process variables were then input into a subroutine for tool wear calculation based on the analytical description of the dominant diamond wear mechanisms during drilling $\mathrm{Al6063} / \mathrm{SiC}_{\mathrm{p}} / 65 \mathrm{p}$ composites. According to the calculated tool nodal wear rate and worn geometry, the tool geometry in finite element codes is updated and new Key files are prepared for the next simulation cycle. 


\subsection{Chip Formation}

\subsubsection{Material Model}

In modelling of forming, manufacturing and structural mechanics, the characterization of material thermomechanical behaviors is often made using a widely-used phenomenological constitutive model. The thermomechanical behaviors of $\mathrm{SiC}_{\mathrm{p}} / \mathrm{Al} 6063$ composites during drilling were reflected by using a phenomenological constitutive model determined through quasi-static and dynamic compression tests. To simulate chip formation during drilling, a generalized Johnson-Cook plasticity model was adopted for describing the material responses of $\mathrm{SiC}_{\mathrm{p}} / \mathrm{Al} 6063$ composites in cutting.

$$
\sigma=\left(A+B \varepsilon_{\mathrm{p}}^{\mathrm{n}}\right)\left[1+C \ln \left(\dot{\varepsilon} / \dot{\varepsilon}_{0}\right)\right]\left(\dot{\varepsilon} / \dot{\varepsilon}_{0}\right)^{\alpha}\left[D-E\left(T^{*}\right)^{\mathrm{m}}\right]
$$

With

$$
\begin{gathered}
T^{*}=\left\{\begin{array}{c}
0 ; T<T_{\text {room }} \\
\left(T-T_{\text {room }}\right) /\left(T_{\text {melt }}-T_{\text {room }}\right) ; T_{\text {room }} \leq T \leq T_{\text {melt }} \\
1 ; T>T_{\text {melt }}
\end{array}\right. \\
D=D_{0} \exp \left[k\left(T-T_{\mathrm{b}}\right)^{\beta}\right]
\end{gathered}
$$

where $A, B, C, \mathrm{n}, \alpha, \mathrm{m}, E, D_{0}, k, \beta$ are material coefficients, $\sigma$ and $\varepsilon_{\mathrm{p}}$ are respectively flow stress and effective plastic strain, $\dot{\varepsilon}_{0}$ is the reference strain rate, $T_{\text {melt }}$ is melting temperature, $T$ workpice temperature and $T_{\text {room }}$ room temperature, $T_{\mathrm{b}}$ reference temperature.

A multi-objective method for model parameters identification proposed in [34] was employed to find a feasible set of parameter estimates so that the formulated plasticity model by these parameters can capture the material behaviors in both quasi-static and dynamic loading modes equally well. Using multi-objective identification strategy, the obtained values of material parameters of the generalized Johnson-Cook plasticity model for $\mathrm{Al} 6063 / \mathrm{SiC}_{\mathrm{p}} / 65$ composites are given in Table 3 . The overall fit standard error and $\mathrm{R}^{2}$ is respectively $18.048 \mathrm{MPa}$ and $97.92 \%$. The good agreement of model prediction with test data under different loading conditions is illustrated in Figure 6. Apart from material parameters for J-C plasticity model, the physical and mechanical properties of Al6063/SiC $/ 65$ composites are presented in Table 4.

Table 3. Material constants for generalized J-C plasticity model for $\mathrm{Al} 6063 / \mathrm{SiC}_{\mathrm{p}} / 65 \mathrm{p}$ composites.

\begin{tabular}{ccccccccccc}
\hline$A / \mathrm{MPa}$ & $\boldsymbol{B} / \mathbf{M P a}$ & $\boldsymbol{C}$ & $\boldsymbol{D}_{\mathbf{0}}$ & $\boldsymbol{E}$ & $\mathbf{n}$ & $\mathbf{m}$ & $\boldsymbol{\alpha}$ & $\boldsymbol{\beta}$ & $\boldsymbol{k}$ & $\boldsymbol{T}_{\mathbf{b}}$ \\
\hline 501 & 449 & 0.0002 & 0.291 & 0.8995 & 0.2539 & 1.602 & 0.0105 & 0.1675 & 0.4781 & 98.2 \\
\hline
\end{tabular}

Table 4. Physical and mechanical properties of $\mathrm{Al6063/SiC} p / 65 p$ composites [34].

\begin{tabular}{ccc}
\hline Notation & Material Properties & Value \\
\hline$\rho_{\mathrm{c}}$ & Density $\left(\mathrm{kg} / \mathrm{m}^{3}\right)$ & 2960 \\
$C_{\mathrm{p}}$ & Specific heat capacity $(\mathrm{J} / \mathrm{kg})$ & 750 \\
$\alpha$ & Coefficient of thermal expansion $\left(10^{-6}\right)$ & 7.7 \\
$\kappa$ & Thermal conductivity $(\mathrm{W} / \mathrm{m} \cdot)$ & 175 \\
$E$ & Elastic modulus $(\mathrm{GPa})$ & 221 \\
$v$ & Poisson's ratio & 0.21 \\
$T_{\text {room }}$ & Room temperature & 20 \\
$T_{\text {melt }}$ & Melting point & 635 \\
$\dot{\varepsilon}_{0}$ & Reference strain rate & 0.01 \\
$\eta$ & Inelastic heat fraction & 0.9 \\
\hline
\end{tabular}




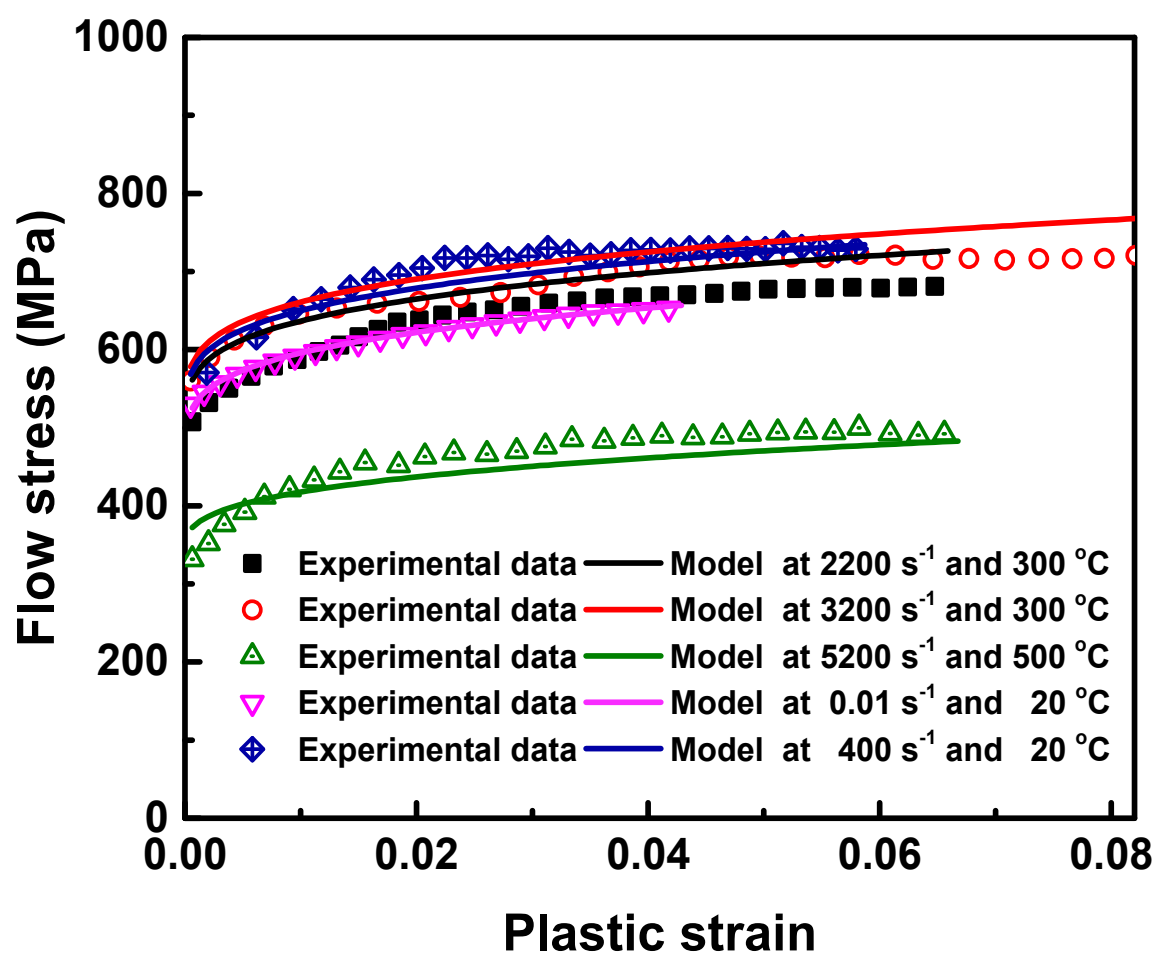

Figure 6. Comparison of the experimental data and prediction results of the identified model through multi-objective strategy.

\subsubsection{Chip Separation}

Chip separation during chip formation is correlated to material failure mechanisms. Generally, the failure mechanisms of particulate reinforced metal matrix composites (PRMMCs) are manifested in: (i) particulate cracking, (ii) debonding interface between particulate and metal matrix and (iii) nucleation, growth and coalescence of voids within metal matrix [35]. Which of the three mechanisms dominated in composites failure is dependent on microstructural morphology information of particulate volume fraction, shape, size, spatial location and on mechanical behavior of metal matrix.

The experimental findings of Lloyd [36] indicate that only when particulate size is $\geq 20 \mu \mathrm{m}$, particulate cracking becomes the dominant failure mode in PRMMCs. This is also confirmed in Xie [37] on the investigation of defect formation mechanism in machining $\mathrm{SiC}_{\mathrm{p}} / \mathrm{Al}$ composites using multi-phase FE model. Provided that reinforcement particulates are distributed uniformly and have no preferred orientation in metal matrix, the area fraction of reinforcement particulates on any cross section with large enough area should be approximately equal to the volume fraction of reinforcement particulates. This paper employed the statistical characterization methodology of PRMMCs proposed by Zhang [38] to quantify the microstructural information and estimated the mean effective diameter of $\mathrm{SiC}$ particulates to be about $4.55 \mu \mathrm{m}$ according to the microstructure containing large numbers of $\mathrm{SiC}$ particulates shown in Figure 7. Therefore, the damage and failure for $\mathrm{Al} 16063 / \mathrm{SiC}_{\mathrm{p}}$ composites is accompanied by the nucleation of microvoids originated from matrix cracking and particulate/matrix interface debonding, growth and coalescence of voids. The fracture morphologies of $\mathrm{Al} 6063 / \mathrm{SiC}_{\mathrm{p}} / 65 \mathrm{p}$ composites after uniaxial compression and machining in Figure 8 are also shown to be made up of dimpled Al matrix, debonded SiC particulates and fewer cracked SiC particulates. As can be seen, the occurrence of damage and failure for $\mathrm{Al} 6063 / \mathrm{SiC}_{\mathrm{p}} / 65 \mathrm{p}$ composites is of localized characteristics and the damage and failure modes involve $\mathrm{Al}$ matrix cracking and interface degradation induced matrix fracture around large numbers of particulate inclusions. 

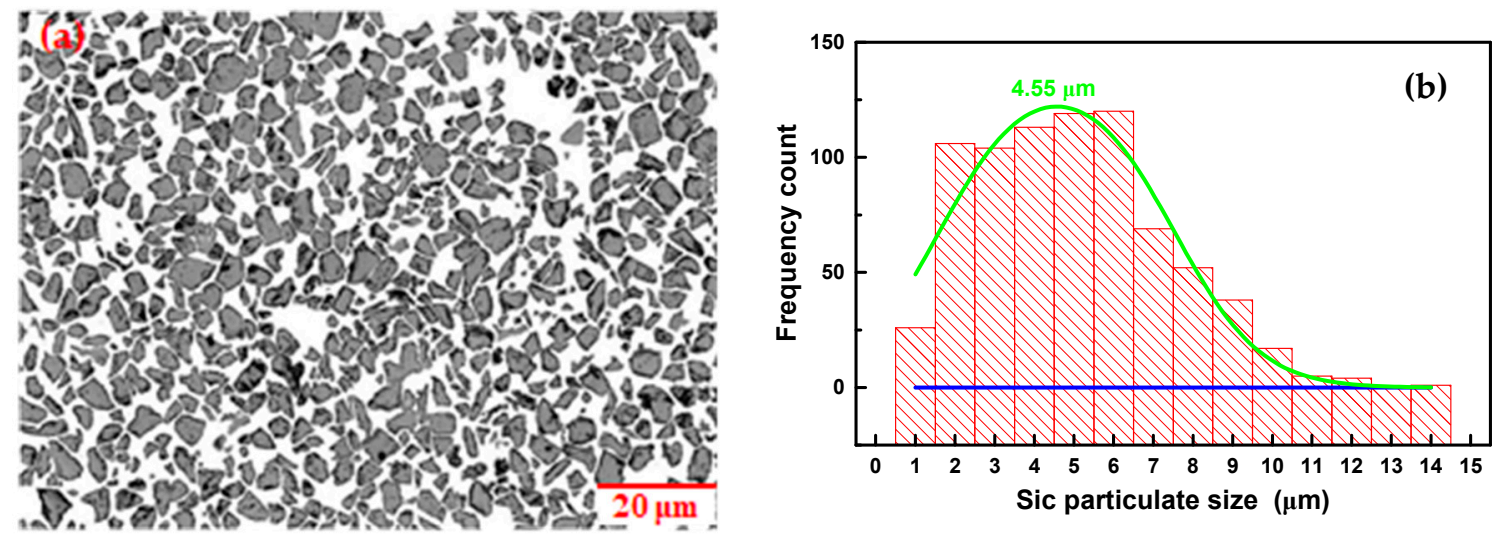

Figure 7. (a) Microstructure and (b) $\mathrm{SiC}$ particulate size distribution of $\mathrm{Al} 6063 / \mathrm{SiC}_{\mathrm{p}} / 65 \mathrm{p}$ composites.

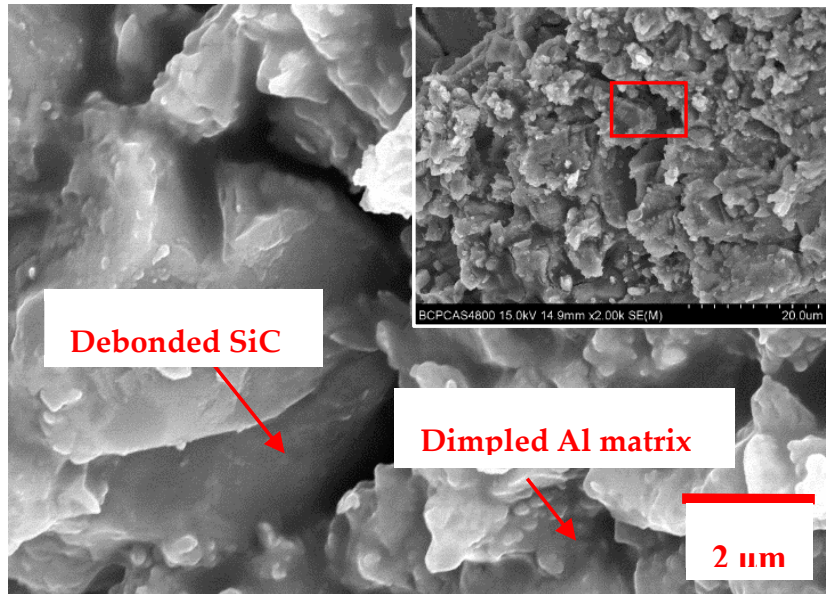

(a)

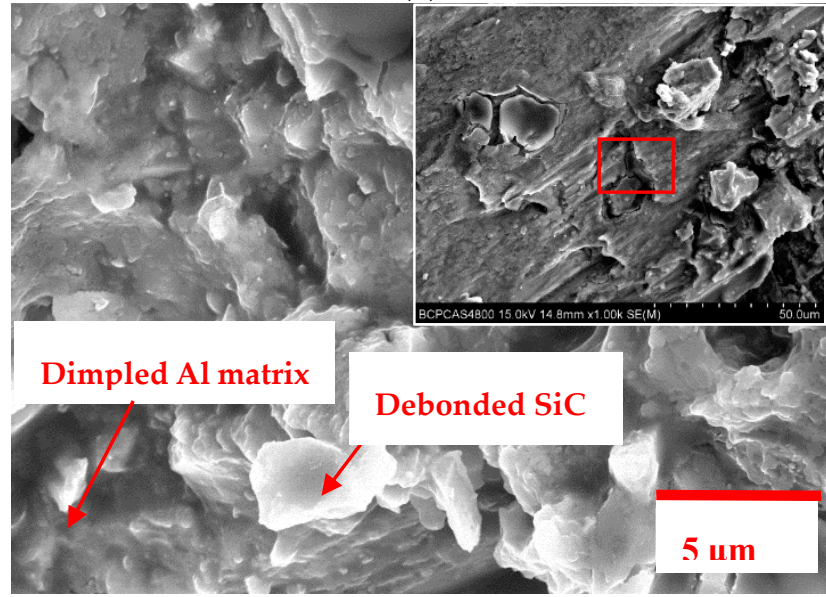

(b)

Figure 8. Fracture morphologies of $\mathrm{Al} 6063 / \mathrm{SiC}_{\mathrm{p}} / 65 \mathrm{p}$ composites after (a) uniaxial compression and (b) machining.

The Cockroft \& Latham damage criterion is shown to be capable of incorporating the tensile stress effect on chip formation during drilling $[39,40]$. Hence, the Cockroft \& Latham damage model is employed for determining material damage and resultant chip segmentation during drilling $\mathrm{Al} 6063 / \mathrm{SiC}_{\mathrm{p}} / 65 \mathrm{p}$ composites. 


$$
D=\int_{0}^{\varepsilon_{f}} \sigma\left(\frac{\sigma^{*}}{\sigma}\right) \mathrm{d} \varepsilon_{\mathrm{p}}
$$

where $D$ is the damage state variable for characterizing continuum damage softening. And when $D$ reaches the critical value $D_{c r}$, the chip separation is triggered by the corresponding elements deletion. $\sigma^{*}$ the maximum principal stress.

\subsection{Heat Generation}

The temperature during cutting process plays a major role in tool wear evolution and wear mechanisms [41]. The heat generation during machining is divided into plastic deformed heat and friction induced heat. Figure 9 shows the schematic of heat partitioning in the chip formation process. The converted heat rate $\dot{q}_{\mathrm{p}}$ by plastic deformation leads to the workpiece temperature variation $\Delta T$ in material forming and machining.

$$
\dot{q}_{\mathrm{p}}=\eta_{\mathrm{p}} \tau_{\Phi} \mathrm{d} \gamma=\rho C_{\mathrm{p}} \Delta T
$$

where $\eta_{\mathrm{p}}$ is Taylor-Quinney coefficient that indicates the fraction of plastic work conversion into heat, $\tau_{\Phi}$ effective adiabatic shear flow stress, $\gamma$ effective plastic shear strain, $\rho$ and $C_{\mathrm{p}}$ the workpiece density and specific heat, respectively.

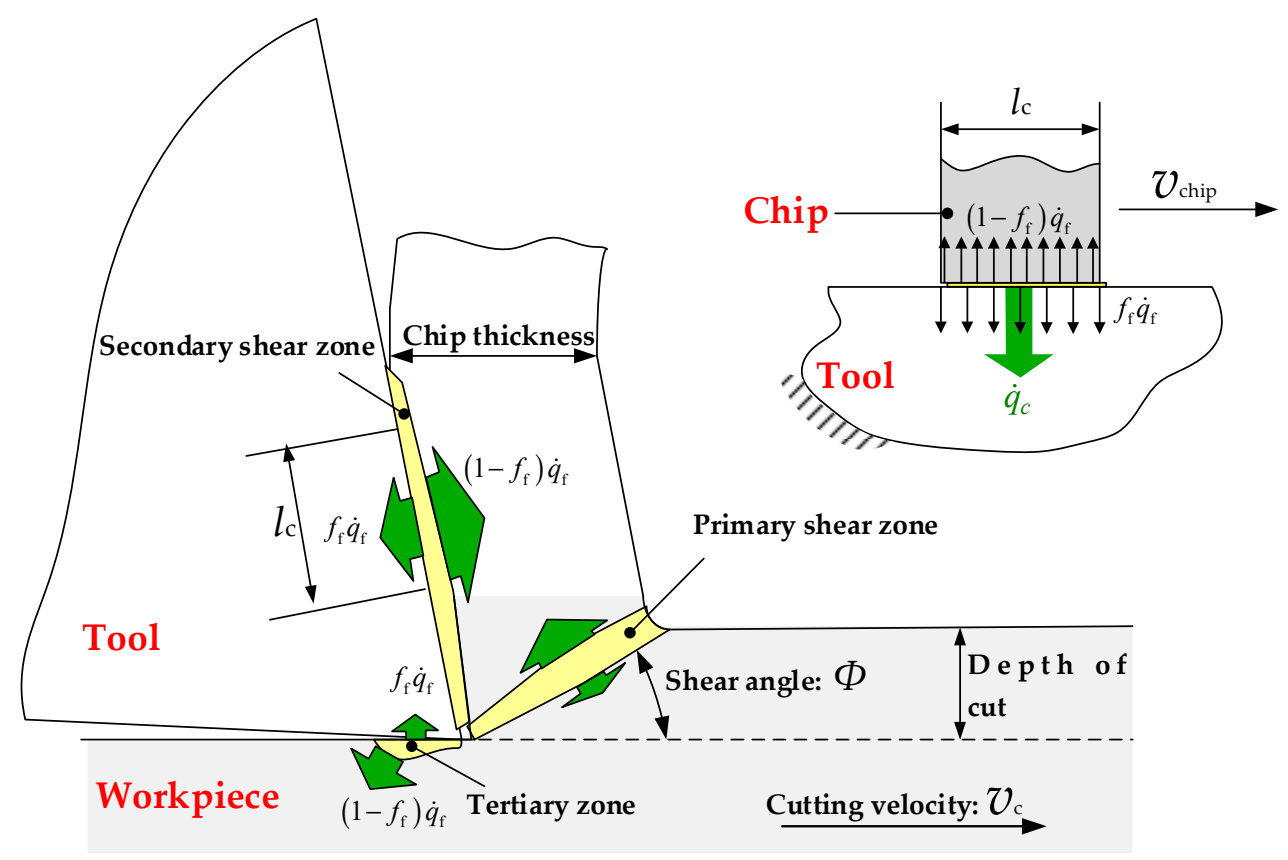

Figure 9. Schematic of heat partitioning in the chip formation process.

The mechanical formulations for sticking and slipping contact along local tangent directions are respectively defined as shear friction and Coulomb friction in terms of the division of slipping $\left(\mu \mathrm{p} \leq \tau_{\text {crit }}\right)$ and sticking ( $\left.\mu \mathrm{p}>\tau_{\text {crit }}\right)$ regions in possible contact domain.

$$
\tau_{\mathrm{f}}=\left\{\begin{array}{l}
\mu \mathrm{p}, \quad \mu \mathrm{p} \leq \tau_{\text {crit }} \\
\tau_{\text {crit }}=m \sigma / \sqrt{3}, \mu \mathrm{p}>\tau_{\text {crit }}
\end{array}\right.
$$


where $\tau_{\text {crit }}$ is the critical shear flow stress, of which the magnitude is generally $\sqrt{3}$ times lower than the tensile yield stress $\sigma, \mathrm{p}$ the chip-tool interface pressure, $\mu$ the friction coefficient. The friction heat $q_{\mathrm{f}}$ at the workpiece-tool interface can be computed according to Equations (6) and (7).

$$
\dot{q}_{\mathrm{f}}=\eta_{\mathrm{f}} \int \tau_{\mathrm{f}} \mathrm{d} v_{\mathrm{s}}
$$

where $\eta_{\mathrm{f}}$ is the converted fraction of friction work into heat, $k_{\text {interface }}$ interface heat transfer coefficient. The amount of heat flux into the tool $\dot{q}_{\mathrm{f}}^{\text {tool }}$ and workpiece $\dot{q}_{\mathrm{f}}^{\text {work }}$ can be given by the following quantitative relations of heat partitioning at the tool-workpiece interface.

$$
\begin{gathered}
\dot{q}_{\mathrm{f}}^{\text {tool }}=f_{\mathrm{f}} \dot{q}_{\mathrm{f}}+\dot{q}_{\mathrm{c}} \\
\dot{q}_{\mathrm{f}}^{\text {work }}=\left(1-f_{\mathrm{f}}\right) \dot{q}_{\mathrm{f}}-\dot{q}_{\mathrm{c}}
\end{gathered}
$$

with

$$
\dot{q}_{\mathrm{c}}=-k_{\mathrm{int}}\left(T_{\mathrm{int}}^{\mathrm{tool}}-T_{\mathrm{int}}^{\mathrm{work}}\right)
$$

where $f_{\mathrm{f}}$ is the fraction of frictional heat flux $q_{\mathrm{f}}$ transferred to tool, $k_{\text {int }}$ the interface heat transfer coefficient, $T_{\text {int }}^{\text {tool }}$ and $T_{\text {int }}^{\text {work }}$ the tool and workpiece temperature near the workpiece-tool interface, respectively.

\subsection{Diamond Wear Modelling}

The rate of volume loss on the tool per unit area per unit time is calculated by a wear rate model considering the predominant wear mechanisms. Due to highly abrasive characteristics of $\mathrm{SiC}_{\mathrm{p}} / \mathrm{Al} 6063$ composites, hence the abrasive model proposed by Usui was adopted to include the contact stress $p$, relative sliding velocity $v_{\mathrm{S}}$ and tool temperature $T$ dependencies. According to the analysis of wear mechanisms in Section 2.2, hence, the coupled abrasive-chemical wear model based description of the dominant wear mechanisms of diamond during drilling $\mathrm{Al} 6063 / \mathrm{SiC}_{\mathrm{p}} / 65 \mathrm{p}$ composites was implemented into a subroutine for tool wear estimate.

$$
\left\{\begin{array}{c}
\frac{\partial W}{\partial \mathrm{t}}=\frac{\partial W_{a}}{\partial \mathrm{t}}=A p v_{\mathrm{S}} \exp \left(-\frac{B}{T}\right) \quad T \leq T_{\text {trans }} \\
\frac{\partial W}{\partial \mathrm{t}}=\frac{\partial W_{a}}{\partial \mathrm{t}}+\frac{\partial W_{\mathrm{g}}}{\partial \mathrm{t}}=A p v_{\mathrm{S}} \exp \left(-\frac{B}{T}\right)+G p^{n} \exp \left(-\frac{E}{R T}\right) T>T_{\text {trans }}, p \leq p_{\text {trans }}
\end{array}\right.
$$

where $\partial W / \partial \mathrm{t}$ is the overall tool wear rate, $\partial W_{a} / \partial \mathrm{t}$ is the wear rate calculated according to Usui abrasive model. $\partial W_{\mathrm{g}} / \partial \mathrm{t}$ is the wear rate calculated according to graphitization induced chemical wear model that extends the Arrhenius law to include pressure-dependence, $E$ activation energy, $R$ gas constant, $A, B, n$ and $G$ experimentally calibrated coefficients. $T_{\text {trans }}$ and $p_{\text {trans }}$ are the activation temperature and pressure for the transformation of diamond into graphite (respectively equal to $500{ }^{\circ} \mathrm{C}$ and $15 \mathrm{GPa}$ under $\mathrm{Cu}$ catalysis) [31].

In this work, the coupled thermomechanical FE model of 3D drilling was applied to drilling process simulation to obtain the distribution of the process variables such as the temperature at the workpiece-tool interface, the relative sliding velocity between the workpiece and tool, contact pressure on the tool surface during drilling. The combined abrasive-chemical wear model in Equation (11) was implemented into an appropriate subroutine for calculating the wear rate and wear variables at the tool nodes in contact with the deforming workpiece by using the available information about thermo-mechanical variables, nodal area and time step. According to the estimated wear rate through the subroutine, the nodal displacement on the tool surface at current time step was computed. The tool geometry was recalculated and updated based on the computed nodal displacement and updated tool. Then a second wear estimate at next time step started with the update worn tool geometry. As this process was repeated, the tool wear evolution was reproduced throughout the machining process. 


\section{Results and Discussions}

\subsection{Cutting Forces}

Based on the experimental details in Table 2, the simulated and experimental cutting forces during drilling $\mathrm{Al} 6063 / \mathrm{SiC}_{\mathrm{p}} / 65 \mathrm{p}$ composites using PCD and CVD drills is presented in Figures 10 and 11. It can be found that the good agreement between simulated and experimental in thrust force is reached except at the beginning stage of drilling. However, the $14.4 \%$ and $10.9 \%$ overestimation for the torque acting on PCD and CVD diamond coated drills may be partly due to the small difference between realistic and simulated tools geometry to which the torque is more sensitive and partly due to the restricted material flow by the fixed lateral wall of the workpiece. As evident, the developed drilling model allowed a fairly accurate prediction of the cutting forces, while it overestimates the torque that has less influence on tool wear. As seen from Figures 10 and 11, under the same cutting conditions, the cutting forces applied on PCD drill was higher than those on CVD diamond coated drill. The increase in cutting forces could result in easy damage and consequent breaking of the chips.

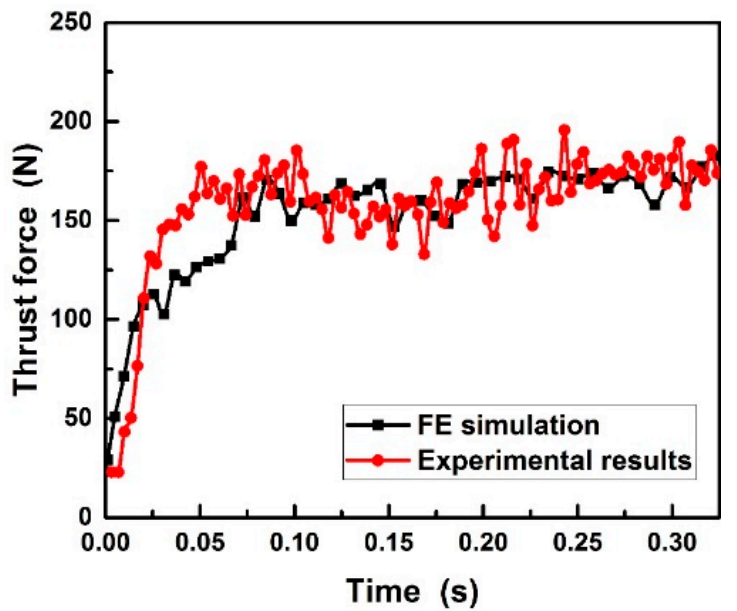

(a)

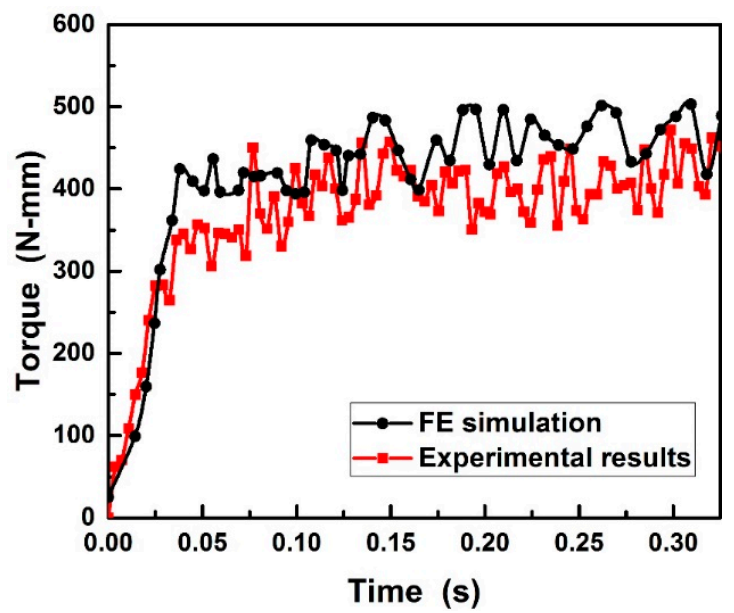

(b)

Figure 10. Comparison of (a) thrust force and (b) torque between FE simulation and experiment during drilling $\mathrm{Al} 6063 / \mathrm{SiC}_{\mathrm{p}} / 65 \mathrm{p}$ composites using brazed PCD drill.

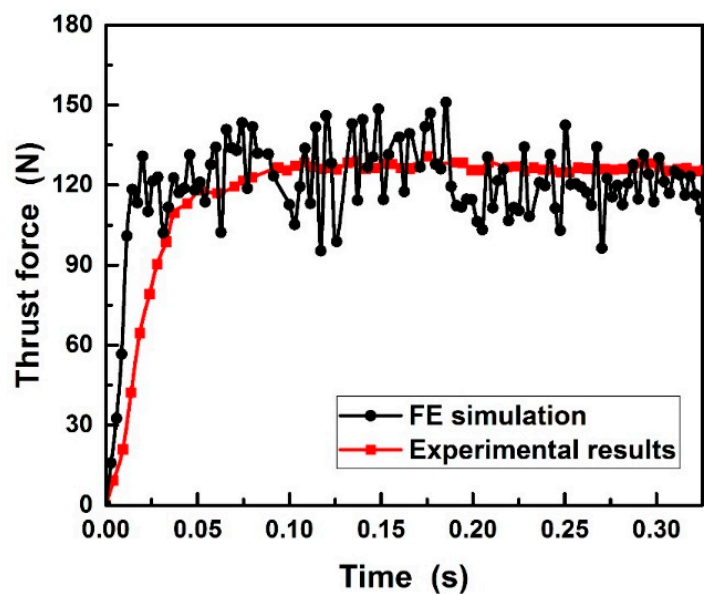

(a)

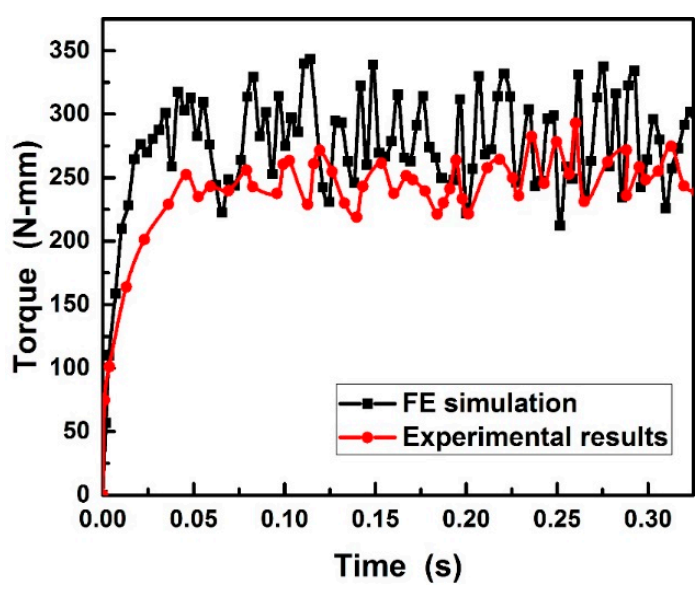

(b)

Figure 11. Comparison of (a) thrust force and (b) torque between FE simulation and drilling experiment performed during drilling $\mathrm{Al} 6063 / \mathrm{SiC}_{\mathrm{p}} / 65 \mathrm{p}$ composites using CVD diamond coated drill. 


\subsection{Chip Morphology}

The disclosure of chip formation mechanism contributes to assisting the redesign of tool geometry and optimizing the machining processes. Comparison of the experimental and simulated morphologies of the chips formed using PCD and CVD diamond coated drills is depicted in Figure 12. The simulated chip shape matched well with experimental obtained chip morphology, especially in chip curling. Additionally, the chip produced by straight cutting lip of PCD drill is more discontinuous and fragmentary than that by curved cutting lip of CVD diamond coated drill during drilling $\mathrm{Al} 6063 / \mathrm{SiC}_{\mathrm{p}} / 65 \mathrm{p}$ composites. As show in Figure 13a, when drilling the corresponding $\mathrm{Al}$ alloy, the force originated from chip formation drives the chip moving up along the flute and rotating by its own chip axis $\omega_{\text {chip }}$, simultaneously the force normal to the flute surface from the drill flute promotes the chip curling by twisting the chip and eventually leads to spiral chip formation during drilling $\mathrm{Al}$ alloy [42]. Whereas, $\mathrm{Al} 6063 / \mathrm{SiC}_{\mathrm{p}} / 65 \mathrm{p}$ composites, having high volume fraction of $\mathrm{SiC}$ reinforcement and consequently low ductility and resistance to bending, generated small fragmentary chips (Figure 13b). The apparent difference of chip morphology during drilling requires in-depth understanding of deformation and failure mechanisms at microstructure scale of $\mathrm{Al}$ alloy and $\mathrm{SiC}_{\mathrm{p}} / \mathrm{Al}$ composites subjected to shear loading that lead to different chip formation.

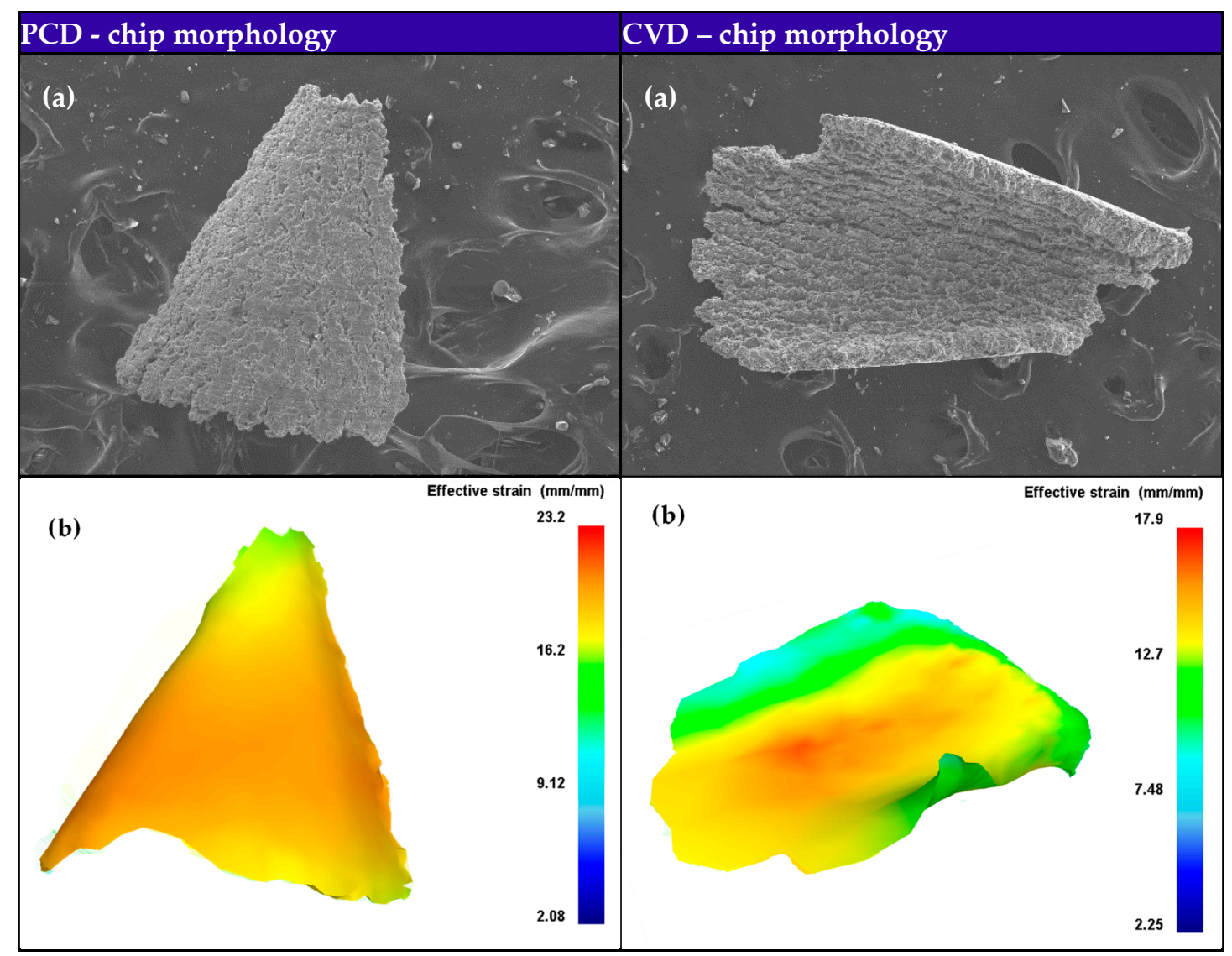

Figure 12. (a) Experimental and (b) simulated morphologies of the chips formed using PCD and CVD drills. 


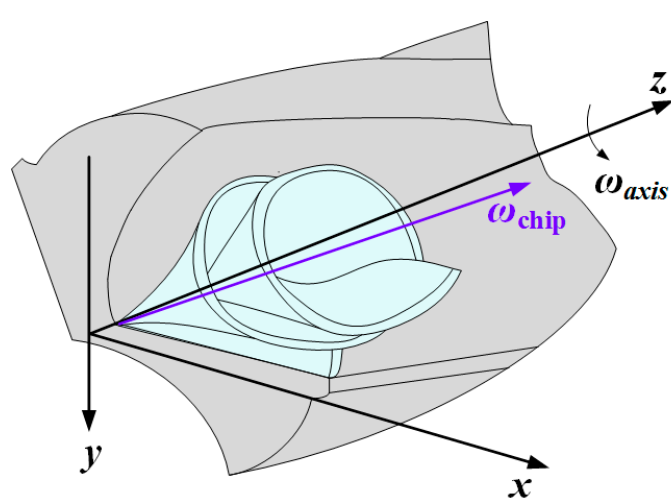

(a)

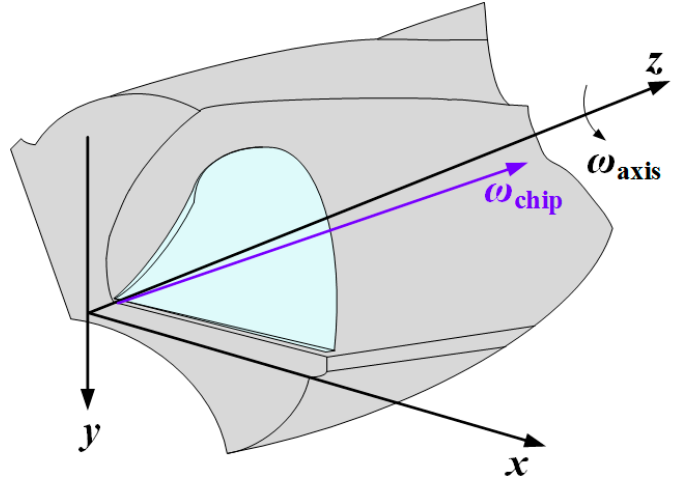

(b)

Figure 13. Schematic of chip formation in drilling of (a) $\mathrm{Al}$ alloy and (b) $\mathrm{SiC}_{\mathrm{p}} / \mathrm{Al}$ composites.

As can be seen from Figure 14, unlike coordinated deformation of $\mathrm{Al}$ grains in drilling $\mathrm{Al}$ alloy, when drilling Al6063/SiC $/$ /65p composites, the localized shear applied by cutting lips would cause the deformation incompatibility of $\mathrm{SiC}$ particulates and $\mathrm{Al}$ grains in the primary shear zone, thus making the microcracks initiated at the interface of $\mathrm{SiC}$ particulates and the $\mathrm{Al}$ matrix due to uncoordinated deformation. Simultaneously, the machining induced compressive stress relief in the freshly generated chip would lead to the formation of a microcracked region with numerous discontinuous cracks in the chip free surface due to the presence of high volume faction brittle phase $\mathrm{SiC}$ in $\mathrm{Al6063} / \mathrm{SiC}_{\mathrm{p}} / 65 \mathrm{p}$ composites (Figure 15). As the drill travels, the newly-formed chip slides outward along the shear plane, meanwhile the microcracked region on the chip free surface propagates further along the rake face. When the chips gradually bend to some extent in which the propagation of the crack to the cutting lip due to microcrack coalescence, sudden brittle fracture of the chip would occur. Therefore, the formed chip when drilling $\mathrm{Al}$ matrix composites reinforced by $\mathrm{SiC}$ particulates is easily broken and fragmented. Additionally, the chip formation is found to be associated with drill geometry, especially drill flute. Often, the more freely the chip moves, the larger the formed chip length is. When the chip comes into the drill flute, the chip motion is impeded by the flute. The flat flute face of PCD drill would restrict the chip curling, while the curved flute face of CVD diamond coated drill can accommodate the curling deformation of the chip. Moreover, compared to the straight lips of PCD drill, the curved lips of CVD diamond coated drill result in larger uncut chip thickness and increased bending strength of the resultant chips, thereby delaying chip-breaking. Therefore, the chip produced using CVD diamond coated drill is longer and bent more severely, compared to that using PCD drill.

(a) Al alloy
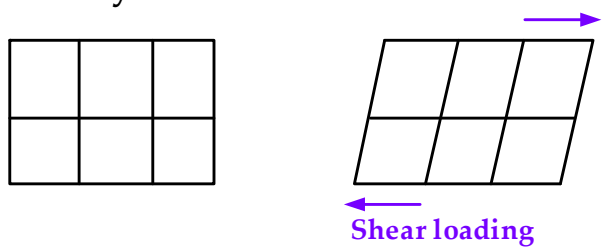

(b) $\mathrm{SiCp} / \mathrm{Al}$ composites
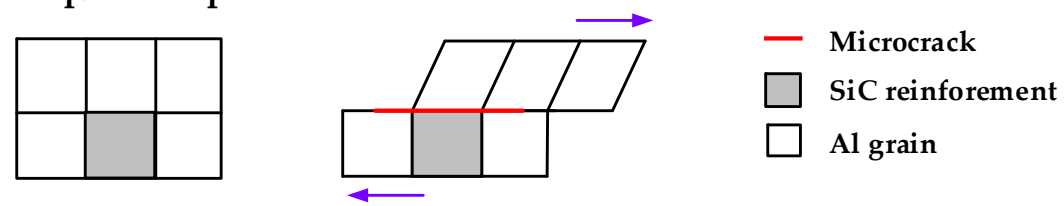

Figure 14. Deformation and failure mechanisms at microstructure scale of (a) $\mathrm{Al}$ alloy and (b) $\mathrm{SiC}_{\mathrm{p}} / \mathrm{Al}$ composites when subjected to shear loading. 


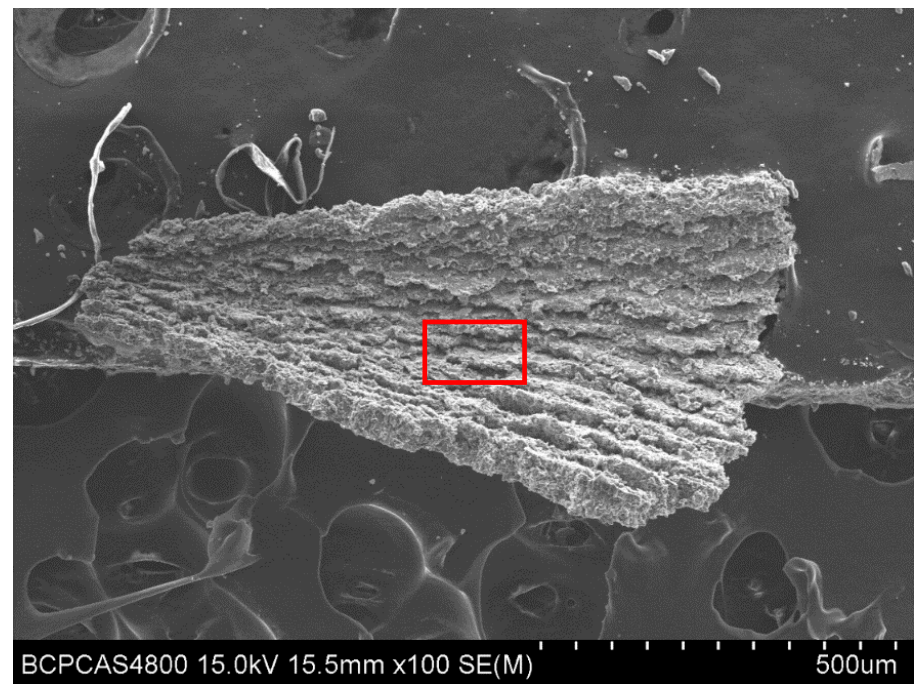

(a)

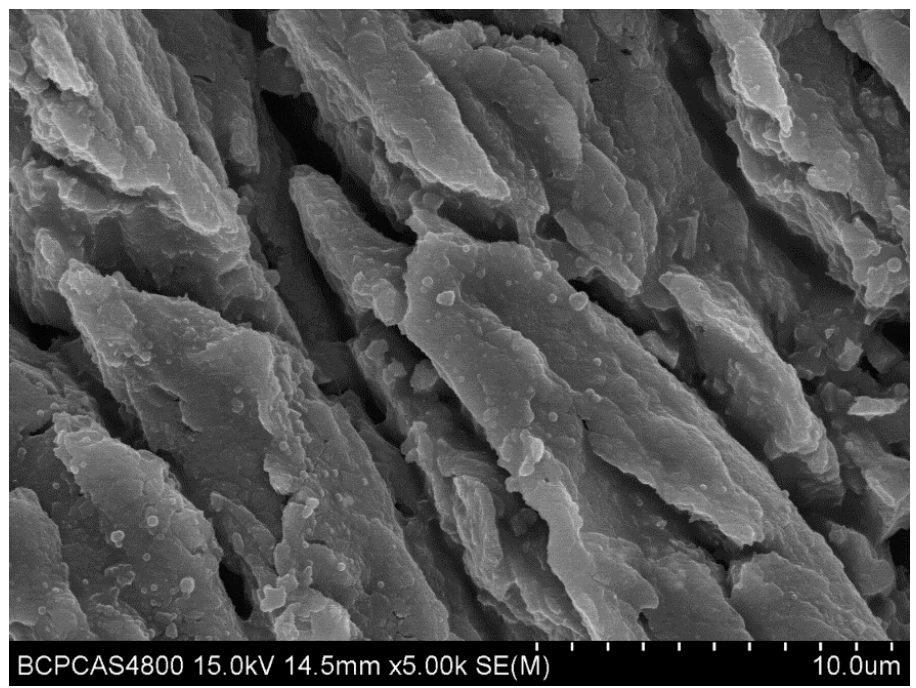

(b)

Figure 15. SEM micrograph of the chip: (a) free surface, (b) image magnification of rectangle region in (a).

\subsection{Tool Temperature}

Increase of the friction force at the tool-chip interface caused by heat localization during high-speed cutting leads to heat localization and high temperature rise in the cutting zone. Consequently, the built-up edge (BUE) often occurs by adhering to the cutting edges of drill bit and this adhesion on the drill surfaces would reduce the hole surface quality and result in the adhesive wear on the cutting edges by intermittent growth and scraping off of BUE. Due to semi-enclosed characteristics of drilling operation, the temperature distribution of drill surface is difficult to measure, especially on the cutting edges. However, a more important issue in tool wear estimate is temperature prediction. To some extent, the distribution of BUE on the drill bit can provide some valuable information and reference about temperature distribution. In Figure 16b, larger high-temperature affected zone is formed on the rake face of PCD drill compared to that of CVD diamond coated drill and thus the larger active area of BUE on the PCD drill than on the CVD diamond coated drill is observed, as shown in Figure 16a. BUE is not observed near the PCD cutting lips, while there exists BUE on the drill faces far away cutting lips. This implies that the BUE formed near cutting lips were scraped off soon due to high-frequency friction effect from SiC particulate. Again, the agreement of experimentally determined BUE distribution on PCD and CVD diamond coated drills bit with numerically simulated 
high-temperature affected zone instills confidence in the developed 3D drilling FE model for tool wear progression.
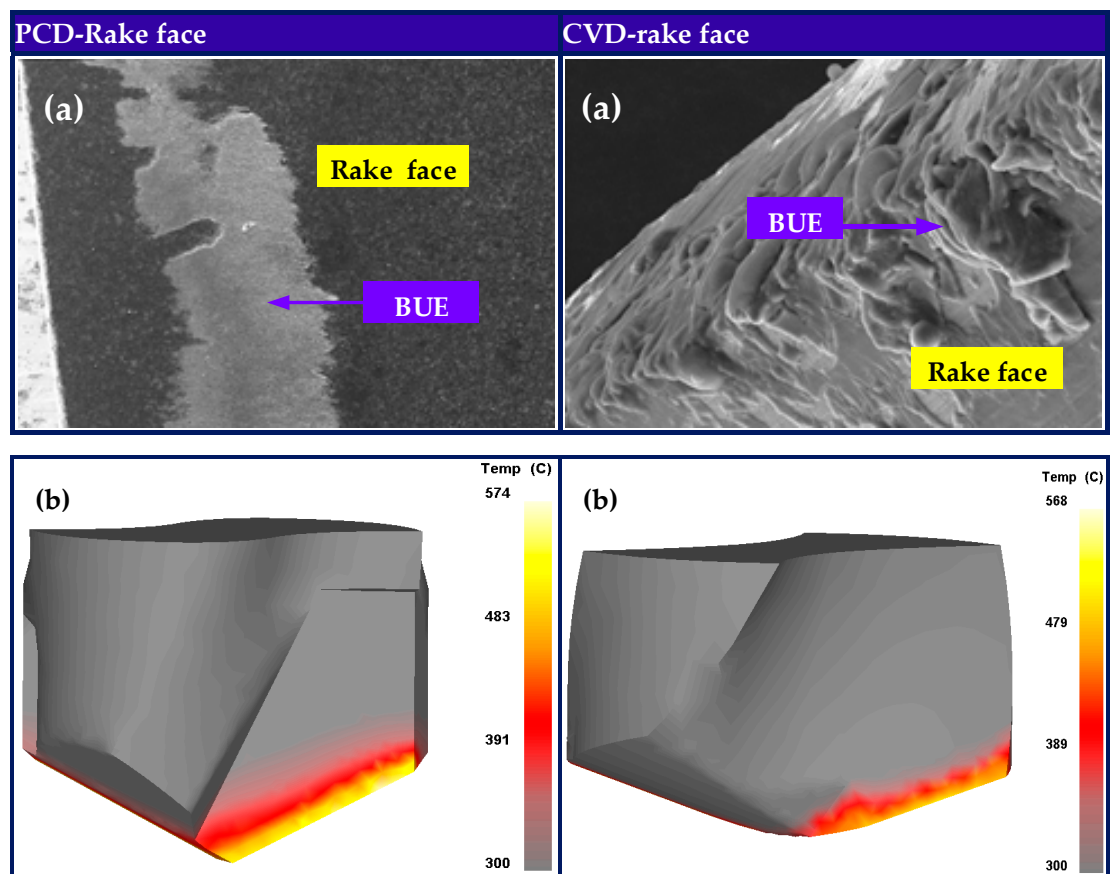

(b)

Temp
568

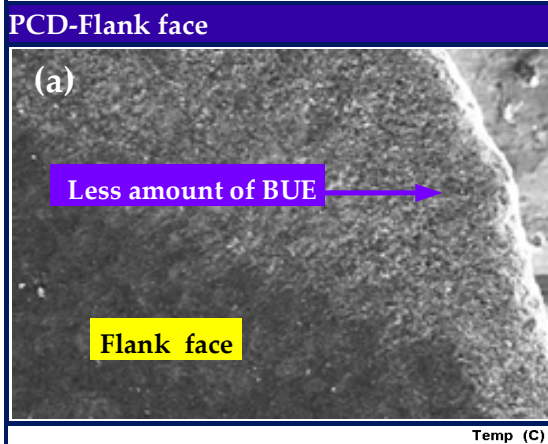

300

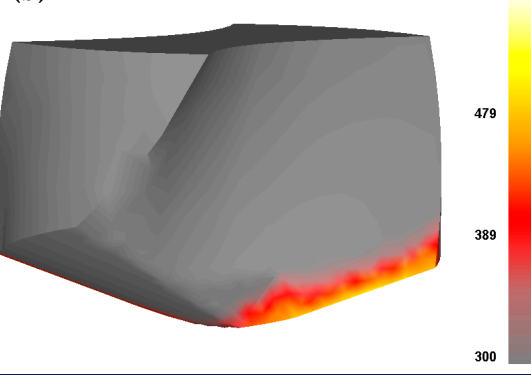

CVD-Flank face

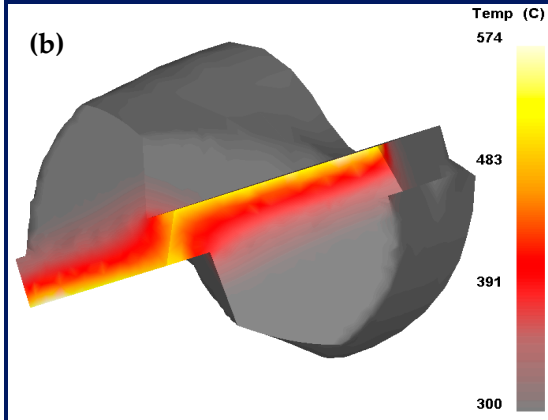

(a)

(b)

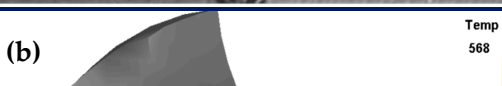

Flank face

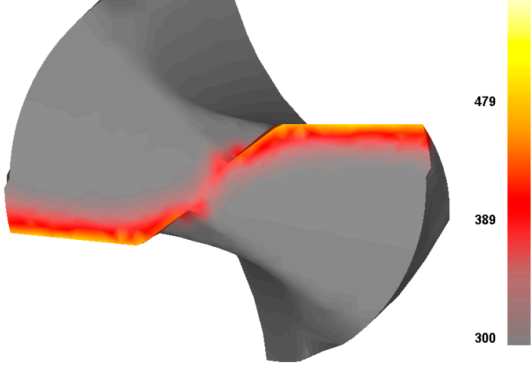

Figure 16. (a) Built-up edge and (b) temperature distribution on rake and flank faces of PCD and CVD diamond coated drills.

\subsection{Tool Wear}

Based on the relative velocity between the drill and chip, the temperature at the drill-chip interface and contact stresses at the drill surface obtained through the coupled thermomechanical analysis of chip formation during 3D drilling, the subroutine for calculating combined abrasive-graphitization wear rate on tool nodes is called to estimate tool wear and update tool geometry. The tool wear calculation cycle is continually repeated until a drilled hole is accomplished. In Figure 17, the experimentally 
observed and numerically simulated wear morphologies of PCD and CVD diamond coated drills are compared after drilling a hole. As can be seen, the presence of graphitization induced chemical wear resulted in the irregular evolution of the simulated tool wear showing a good agreement with experimental observations, compared to even wear morphology caused by only abrasive wear. PCD drill with straight cutting lips suffered form more severe wear than CVD diamond coated drill with curved cutting lips in drilling Al6063/ $\mathrm{SiC}_{\mathrm{p}} / 65 \mathrm{p}$ composites, especially in chisel edge. Table 5 shows the comparison of the maximum flank wear width (MFWW) between experiment and FE simulation. The similar wear morphologies and matched MWFW of both PCD and CVD diamond coated drills between experimental results and model prediction validate the feasibility and reliability of the developed 3D tool wear FE model based analytical description of the dominant diamond wear mechanisms taking into account the abrasion and graphitization.
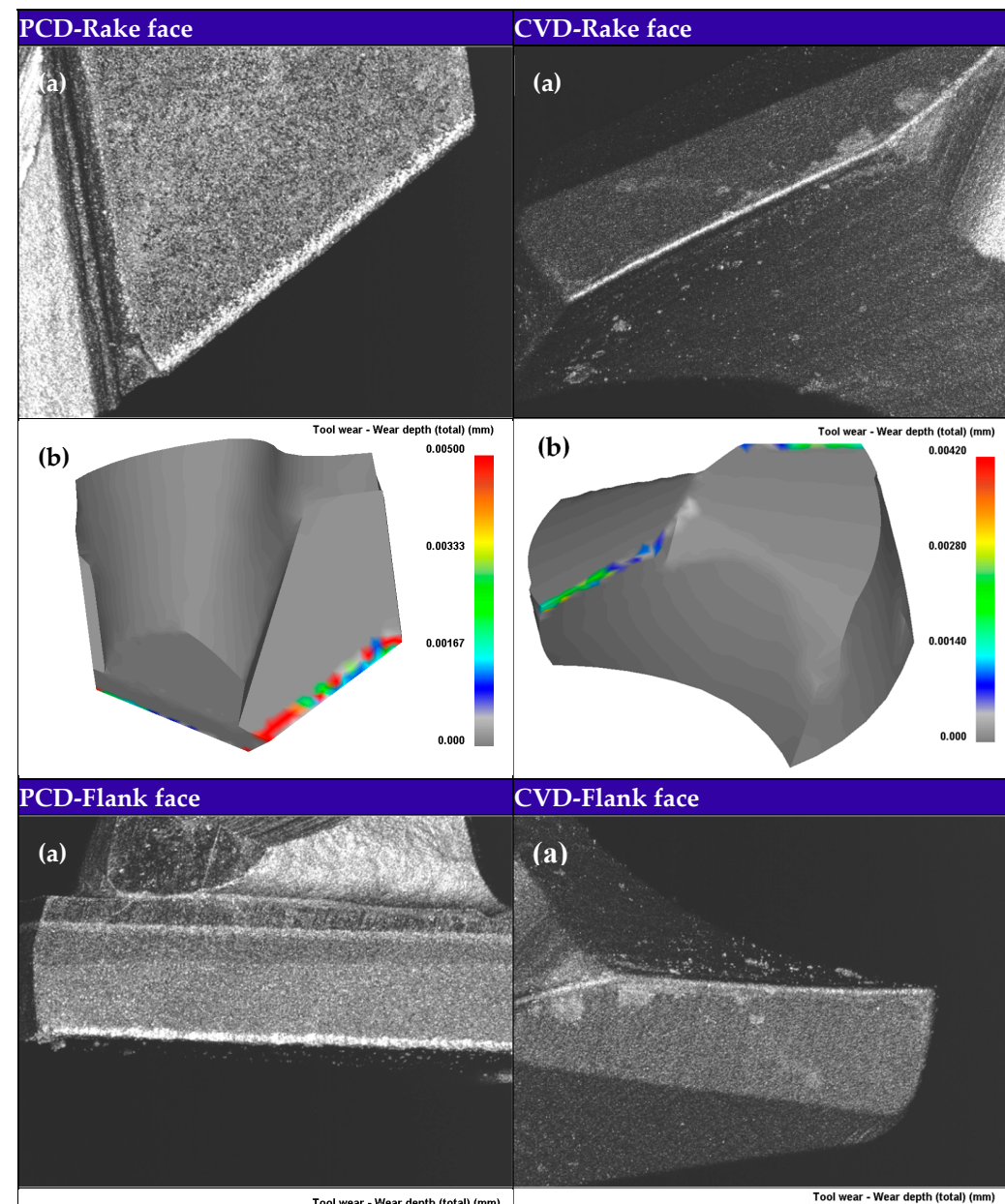

CVD-Flank face

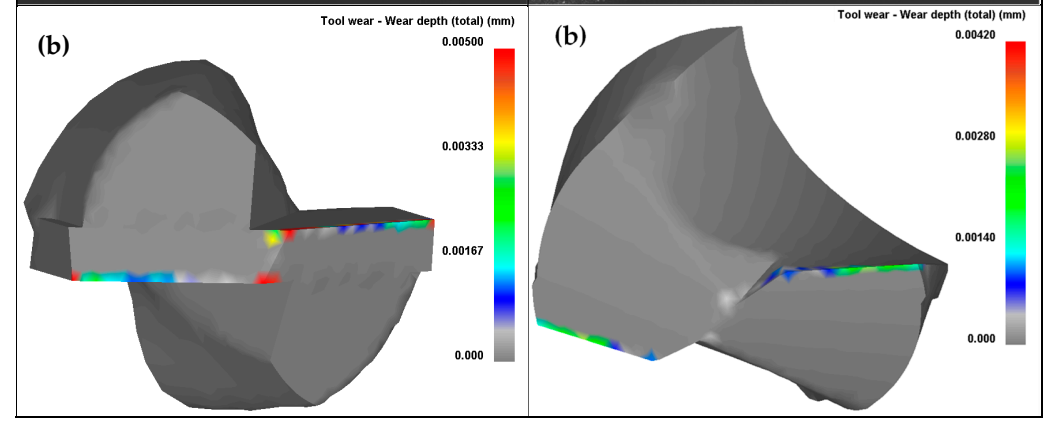

Figure 17. Cont. 


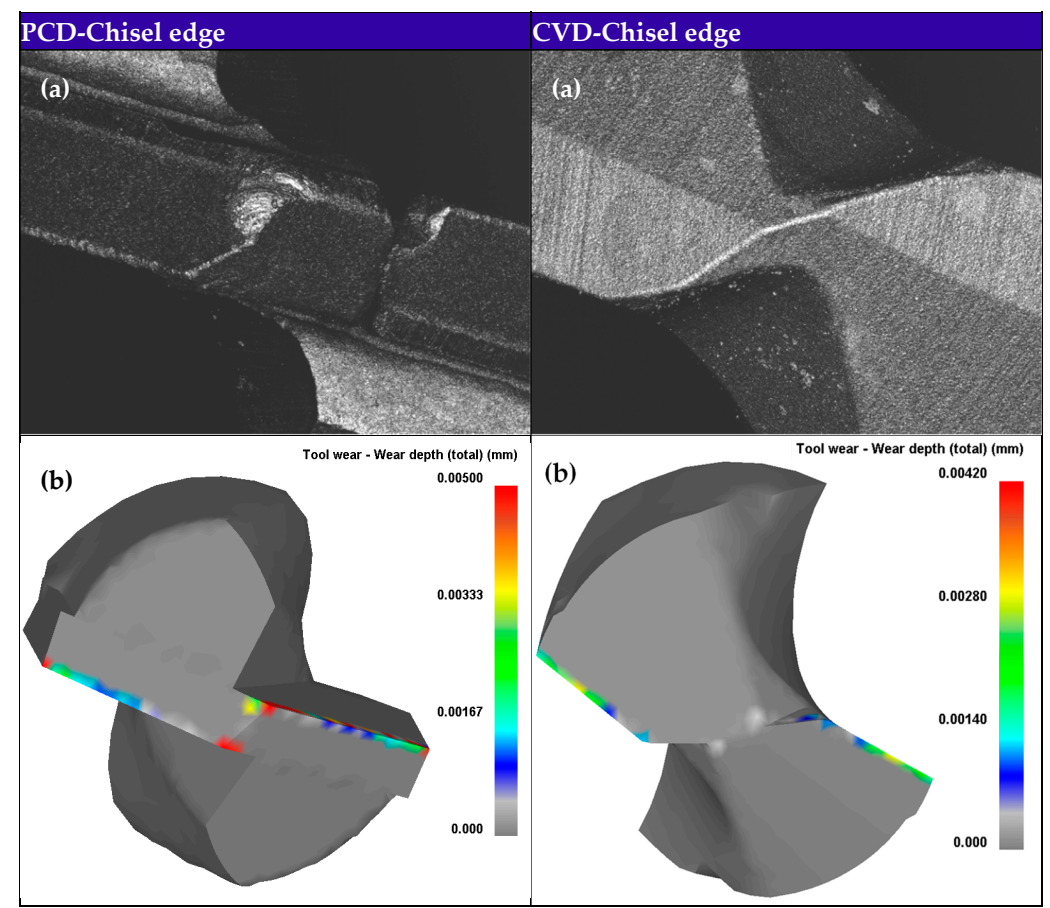

Figure 17. (a) Experimental and (b) simulated wear morphologies of PCD and CVD drills after drilling a hole.

Table 5. Comparison of the MFWW between experiment and FE simulation.

\begin{tabular}{cccc}
\hline Cutting Tool & Experimental MFWW & Simulated MFWW & Relative Error \\
\hline PCD & $43.237 \mu \mathrm{m}$ & $47.544 \mu \mathrm{m}$ & $9.96 \%$ \\
CVD & 38.119 & $37.608 \mu \mathrm{m}$ & $1.34 \%$ \\
\hline
\end{tabular}

\section{Conclusions}

In this paper, an attempt was made to predict the wear evolution of diamond tools during drilling $\mathrm{SiC}_{\mathrm{p}} / \mathrm{Al}$ composites by using the developed drilling FE model based analytical description of the dominant diamond wear mechanisms. The diamond tool wear in drilling $\mathrm{SiC}_{\mathrm{p}} / \mathrm{Al} 6061$ composites is mainly attributed to the combined effects of abrasion from SiC particulates and graphitization catalyzed by $\mathrm{Cu}$ in the Al6061 matrix. The combined abrasive-chemical wear model coupling Usui abrasive model and Arrhenius extended graphitization wear model was implemented by a user-defined subroutine for the tool wear rate estimate that is formulated by some process variables such as the relative velocity between the drill and chip, the temperature at the drill-chip interface and contact stresses at the drill surface. These process variables can be available from the coupled thermomechanical FE analysis of 3D drilling. The developed FE model for tool wear estimate was validated for feasibility and reliability by comparing numerically simulated tool wear morphology and experimentally observed results after drilling a hole using PCD and CVD diamond coated drills. The similar cutting forces, chip and tool wear morphologies between experimental results and model prediction indicate that the developed 3D drilling FE model, combined with a subroutine for tool wear estimate can provide good prediction not only in cutting forces and chip shape but also in tool wear behavior. The presence of graphitization induced chemical wear resulted in the irregular evolution of the simulated tool wear, which demonstrates a good agreement with experimentally observed tool wear. Hence, it is possible to utilize the tool wear FE simulation based analytical description of the dominant wear mechanisms to estimate the overall tool wear.

The developed diamond tool wear FE model can be feasibly extended to the investigation of diamond tool wear evolution with various diamond tool geometries in cutting different workpiece 
materials once calibrated the tool wear model and determined the workpiece constitutive model. Capability of evaluating the dominant diamond wear mechanisms effects on tool wear contributes to the redesign of tool geometry and optimization of cutting process.

Acknowledgments: This work is supported by the National Natural Science Foundation of China under Grant No. 51575051.

Author Contributions: Junfeng Xiang developed FEM codes and wrote this paper; Lijing Xie and Siqin Pang proposed some ideas for this paper and helped to correct it. Feinong Gao assisted the design of the cutting experiments and analyzed the related data. Xin $\mathrm{Hu}$, Fang $\mathrm{Hu}$ and Jie Yi helped to perform the cutting tests and the relative microstructural analysis of tool wear morphology.

Conflicts of Interest: The authors declare no conflict of interest.

\section{References}

1. Dong, Z.; Zheng, F.; Zhu, X.; Kang, R.; Zhang, B. Characterization of material removal in ultrasonically assisted grinding of $\mathrm{SiC}_{\mathrm{p}} / \mathrm{Al}$ with high volume fraction. Int. J. Adv. Manuf. Technol. 2017, 93, 2827-2839. [CrossRef]

2. Ozben, T.; Kilickap, E.; Çakır, O. Investigation of mechanical and machinability properties of SiC particle reinforced Al-MMC. J. Mater. Process. Technol. 2008, 198, 220-225. [CrossRef]

3. Wang, B.; Zhao, S.; Ojima, F.; Yang, J.; Ishizaki, K. Pulse electric current sintering of 3D interpenetrating $\mathrm{SiC} / \mathrm{Al}$ composite. Ceram. Int. 2017, 43, 2867-2870. [CrossRef]

4. Chen, X.; Xie, L.; Xue, X.; Wang, X. Research on 3D milling simulation of $\mathrm{SiC}_{\mathrm{p}} / \mathrm{Al}$ composite based on a phenomenological model. Int. J. Adv. Manuf. Technol. 2017, 92, 2715-2723. [CrossRef]

5. Palanikumar, K.; Muniaraj, A. Experimental investigation and analysis of thrust force in drilling cast hybrid metal matrix (Al-15\% SiC-4\% graphite) composites. Measurement 2014, 53, 240-250. [CrossRef]

6. Das, S.; Behera, R.; Majumdar, G.; Oraon, B.; Sutradhar, G. An experimental investigation on the machinability of powder formed silicon carbide particle reinforced aluminium metal matrix composites. Int. J. Heat Mass Transf. 2007, 50, 5054-5064.

7. Muthukrishnan, N.; Murugan, M.; Rao, K.P. An investigation on the machinability of Al-SiC metal matrix composites using PCD inserts. Int. J. Adv. Manuf. Technol. 2008, 5-6, 447-454. [CrossRef]

8. Feng, P.; Liang, G.; Zhang, J. Ultrasonic vibration-assisted scratch characteristics of silicon carbide-reinforced aluminum matrix composites. Ceram. Int. 2014, 40, 10817-10823. [CrossRef]

9. Ding, X.; Liew, W.Y.H.; Liu, X.D. Evaluation of machining performance of MMC with PCBN and PCD tools. Wear 2005, 259, 1225-1234. [CrossRef]

10. Han, J.; Hao, X.; Li, L.; Wu, Q.; He, N. Milling of high volume fraction $\mathrm{SiC}_{\mathrm{p}} / \mathrm{Al}$ composites using PCD tools with different structures of tool edges and grain sizes. Int. J. Adv. Manuf. Technol. 2017, 92, 1875-1882. [CrossRef]

11. Bushlya, V.; Lenrick, F.; Gutnichenko, O.; Petrusha, I.; Osipov, O.; Kristiansson, S.; Stahl, J.E. Performance and wear mechanisms of novel superhard diamond and boron nitride based tools in machining $\mathrm{Al}-\mathrm{SiC}_{\mathrm{p}}$ metal matrix composite. Wear 2017, 376-377, 152-164. [CrossRef]

12. Schmauder, S.; Schäfer, I. Multiscale materials modeling. Mater. Today 2016, 19, 130-131. [CrossRef]

13. Li, B. A review of tool wear estimation using theoretical analysis and numerical simulation technologies. Int. J. Refract. Met. Hard Mater. 2012, 35, 143-151. [CrossRef]

14. Zhang, S.J.; To, S.; Zhang, G.Q. Diamond tool wear in ultra-precision machining. Int. J. Adv. Manuf. Technol. 2016, 88, 613-641. [CrossRef]

15. Colding, B.N. Machinability of metals and machining costs. Int. J. Mach. Tool Des. Res. 1961, 1, $220-248$. [CrossRef]

16. Choudhury, S.K.; Rao, I.V.K.A. Optimization of cutting parameters for maximizing tool life. Int. J. Mach. Tools Manuf. 1999, 39, 343-353. [CrossRef]

17. Marksberry, P.W.; Jawahir, I.S. A comprehensive tool-wear/tool-life performance model in the evaluation of NDM (near dry machining) for sustainable manufacturing. Int. J. Mach. Tools Manuf. 2008, 48, 878-886. [CrossRef]

18. Tool Life Testing in Milling; International Standard 8688-2-1989; International Organization for Standardization: Geneva, Switzerland, 1989.

19. Li, K.; Gao, X.L.; Sutherland, J.W. Finite element simulation of the orthogonal metal cutting process for qualitative understanding of the effects of crater wear on the chip formation process. J. Mater. Process. Technol. 2002, 127, 309-324. [CrossRef] 
20. Snr, D.E.D. Sensor signals for tool-wear monitoring in metal cutting operations-A review of methods. Int. J. Mach. Tools Manuf. 2000, 40, 1073-1098. [CrossRef]

21. Takeyama, H.; Murata, R. Basic investigation of tool wear. J. Eng. Ind. 1963, 85, 33. [CrossRef]

22. Usui, E.; Shirakashi, T.; Kitagawa, T. Analytical prediction of cutting tool wear. Wear 1984, 100, $129-151$. [CrossRef]

23. Shaw, M.C.; Dirke, S.O. On the wear of cutting tools. Microtecnic 1956, 10, 187. [CrossRef]

24. Attanasio, A.; Ceretti, E.; Fiorentino, A.; Cappellini, C.; Giardini, C. Investigation and FEM-based simulation of tool wear in turning operations with uncoated carbide tools. Wear 2010, 269, 344-350. [CrossRef]

25. Jiang, H. A cobalt diffusion based model for predicting crater wear of carbide tools in machining titanium alloys. J. Eng. Mater. Technol. ASME 2005, 127, 136-144. [CrossRef]

26. López de Lacalle, L.N.; Lamikiz, A. Mechanistic model for drills with double point-angle edges. Int. J. Adv. Manuf. Technol. 2009, 40, 447-457. [CrossRef]

27. Xie, L.J.; Schmidt, J.; Schmidt, C.; Biesinger, F. 2D FEM estimate of tool wear in turning operation. Wear 2005, 258, 1479-1490. [CrossRef]

28. Attanasio, A.; Ceretti, E.; Rizzuti, S.; Umbrello, D.; Micari, F. 3D finite element analysis of tool wear in machining. CIRP Ann.-Manuf. Technol. 2008, 57, 61-64. [CrossRef]

29. Narulkar, R.; Bukkapatnam, S.; Raff, L.M.; Komanduri, R. Graphitization as a precursor to wear of diamond in machining pure iron: A molecular dynamics investigation. Comp. Mater. Sci. 2009, 45, 358-366. [CrossRef]

30. Bródka, A.; Zerda, T.W.; Burian, A. Graphitization of small diamond cluster-Molecular dynamics simulation. Diam. Relat. Mater. 2006, 15, 1818-1821. [CrossRef]

31. Xiang, J.; Xie, L.; Gao, F.; Yi, J.; Pang, S.; Wang, X. Diamond tools wear in drilling of $\mathrm{SiC}_{\mathrm{p}} / \mathrm{Al}$ matrix composites containing Copper. Ceram. Int. 2018, 44, 5341-5351. [CrossRef]

32. Chou, Y.K.; Liu, J. CVD diamond tool performance in metal matrix composite machining. Surf. Coat. Technol. 2005, 200, 1872-1878. [CrossRef]

33. Rodríguez-Barrero, S.; Fernández-Larrinoa, J.; Azkona, I.; López de Lacalle, L.N.; Polvorosa, R. Enhanced performance of nanostructured coatings for drilling by droplet elimination. Mater. Manuf. Process. 2016, 31, 593-602. [CrossRef]

34. Xiang, J.; Xie, L.; Gao, F.; Zhang, Y.; Yi, J.; Pang, S.; Wang, X. On multi-objective based constitutive modelling methodology and numerical validation in small-hole drilling of Al6063/SiC p composites. Materials 2018, 11, 97. [CrossRef] [PubMed]

35. Li, Y.; Ramesh, K.T.; Chin, E.S.C. Viscoplastic deformations and compressive damage in an $\mathrm{A} 359 / \mathrm{SiC}_{\mathrm{p}}$ metal-matrix composite. Acta Mater. 2000, 48, 1563-1573. [CrossRef]

36. Lloyd, D.J. Aspects of fracture in particulate reinforced metal matrix composites. Acta Metall. Mater. 1991, 39, 59-71. [CrossRef]

37. Wang, T.; Xie, L.; Wang, X. Simulation study on defect formation mechanism of the machined surface in milling of high volume fraction $\mathrm{SiC}_{\mathrm{p}} / \mathrm{Al}$ composite. Int. J. Adv. Manuf. Technol. 2015, 79, 1185-1194. [CrossRef]

38. Zhang, P.; Li, F. Statistical analysis of reinforcement characterization in SiC particle reinforced $\mathrm{Al}$ matrix composites. J. Mater. Sci. Technol. 2009, 25, 807-813. [CrossRef]

39. Pujana, J.; Rivero, A.; Celaya, A.; López de Lacalle, L.N. Analysis of ultrasonic-assisted drilling of Ti6Al4V. Int. J. Mach. Tools Manuf. 2009, 49, 500-508. [CrossRef]

40. Gandarias, A.; López de Lacalle, L.N.; Aizpitarte, X.; Lamikiz, A. Study of the performance of the turning and drilling of austenitic stainless steels using two coolant techniques. Int. J. Mach. Mach. Mater. 2008, 3, 1-17. [CrossRef]

41. Calatoru, V.D.; Balazinski, M.; Mayer, J.R.R.; Paris, H.; L'Espérance, G. Diffusion wear mechanism during high-speed machining of 7475-T7351 aluminum alloy with carbide end mills. Wear 2008, 265, 1793-1800. [CrossRef]

42. Batzer, S.A.; Haan, D.M.; Rao, P.D.; Olson, W.W.; Sutherland, J.W. Chip morphology and hole surface texture in the drilling of cast Aluminum alloys. J. Mater. Process. Technol. 1998, 79, 72-78. [CrossRef]

(C) 2018 by the authors. Licensee MDPI, Basel, Switzerland. This article is an open access article distributed under the terms and conditions of the Creative Commons Attribution (CC BY) license (http:/ / creativecommons.org/licenses/by/4.0/). 